\title{
Imigrantes em um continente perdido: 0 registro fossilífero de roedores Caviomorpha (Mammalia: Rodentia: Ctenohystrica) do Cenozoico do Brasil
}

\author{
Immigrants on a lost continent: The fossiliferous record of Caviomorpha rodents (Mammalia: Rodentia: CTenohystrica) \\ from the Cenozolc of Brazil \\ LeONARDo Kerber ${ }^{1}$ \\ 1 - Progr. Pós-Grad. Biodiv. Animal, Univ. Fed. Santa Maria. CAPPA - Centro Apoio Pesq. Paleont. da Quarta Colônia, Univ. Fed. Santa \\ Maria, São João do Polêsine, Brasil. email: leonardokerber@gmail.com
}

ABSTRACT: Rodentia is one of the most diversified placental mammal group. The members of this clade inhabit all continents with exception of the Antarctic. Caviomorpha is a South American group, which appeared in the fossil record during the middle Eocene, and irradiate during the Cenozoic, mainly in the late Oligocene and middle/late Miocene. Herein, the Brazilian fossil record of caviomorphs is reviewed. Discussion concerning morphology, lifestyle, evolution and the implications of the Brazilian fossil record are provided. Fossils assigned to following groups have been recovered in our country: Erethizontidae (Erethizontoidea), Echimyidae, Ctenomyidae (Octodontoidea), Caviidae (including Hydrochoerinae), Dasyproctidae, Cuniculidae (Cavioidea), Chinchillidae, Dinomyidae and Neoepiblemidae (Chinchilloidea). The fossils from this portion of the continent have told part of the evolutionary history of Caviomorpha during the late Oligocene, Neogene, and Quaternary. As future perspectives in the study of Brazilian fossil rodents, it is expected that collection of new specimens with stratigraphic control, review of fossils housed in scientific collections, and increase in the knowledge on the morphology of the taxonomic units, will contribute to a better understanding of the diversity and evolution of this group.
Manuscrito:

Recebido: 06/01/2017

Corrigido: 13/07/2017

Aceito: 07/08/2017

Citation: Kerber L. 2017. Imigrantes em um continente perdido: 0 registro fossilífero de roedores Caviomorpha (Mammalia: Rodentia: Ctenohystrica) do Cenozoico do Brasil. Terræ Didatica, 13(2):185-211. < http:// www.ige.unicamp.br/terraedidatica/>.

Keywords: Caviomorphs, evolutionary history, paleobiogeography, Paleogene, Neogene, Quaternary.

\section{Introdução}

\begin{abstract}
"From the point of view of studies in evolution, however, the rodents are among the most important orders of mammals. There are several reasons for this: rodents now make up about two thirds of the number of mammalian species in the world, and there is every evidence that they have been equally abundant throughout most of the Tertiary; the rodents, being a single order of such great size, illustrate parallelism and convergence in evolution better than any other group of mammals." (Albert E. Wood) ${ }^{1}$
\end{abstract}

Dentre os mamíferos, os roedores (Mammalia: Rodentia) formam um grupo claramente distinguível. Entre todas as características que definem esse clado (Hartenberg 1985, Novacek 1985, Landry Jr. 1999, Archibald et al. 2001, Meng \& Wyss 2005), a mais evidente é presença de dentição altamente

1 Wood, A.E. 1947. Rodents. A study in evolution. Evolution, 1(3):154-162. especializada somada ao peculiar modo de mastigação desses animais. A dentição inclui um par de incisivos superiores e inferiores de crescimento contínuo com esmalte somente na face labial, um amplo diastema seguido por pré-molares (em menor quantidade que outros grupos de mamíferos e as vezes totalmente ausentes) e molares. $\mathrm{O}$ sistema mastigatório dos roedores realiza o movimento propalinal, ou seja, o deslocamento anteroposterior da mandíbula em relação ao crânio, que origina o movimento responsável pelo hábito de "roer", característica que dá nome ao clado. Esse movimento é permitido pela ausência de caninos e pela articulação do côndilo mandibular do dentário e fossa glenoide, que é em forma de uma canaleta anteroposteriormente alongada, onde desloca-se o côndilo. Durante o movimento, ocorre atrito entre os incisivos, que desgasta a dentina exposta na face lingual destes dentes dando o aspecto de "cinzel" para os mesmos (Fig. 1) 


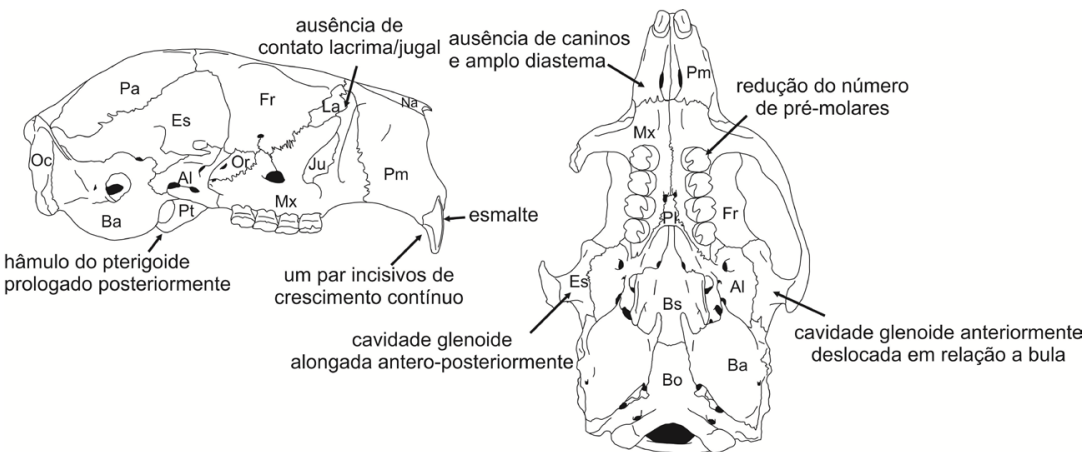

Figura 1. Algumas características do crânio de Rodentia [Coendou spinosus (F. Cuvier, 1823)]. Vista lateral e ventral respectivamente. Abreviaturas: Al, aliesfenoide; Ba, auditiva; Bo, basioccipital; Bs, basiesfenoide; Es, esquamosal; Fr, frontal; Ju, jugal; La, lacrimal; Mx; maxila; Na, nasal; Oc, occipital; Or, orbitoesfenoide; Pa, parietal; $\mathrm{Pl}$, palatino; $\mathrm{Pm}$, pré-maxila

Roedores compõem um dos grupos de mamíferos mais diversificados, representando cerca de $40 \%$ da diversidade de mamíferos atuais, com 2.227 espécies viventes, distribuídas em 34 "famílias" que habitam todos os continentes, com exceção da Antártida (Woods \& Kilpatrick 2005). Tamanha é a diversidade do clado que novos táxons viventes vêm sendo descritos a cada ano, incluindo formas que apresentam peculiaridades morfológicas antes desconhecidas pela ciência (e.g. Esselstyn et al. 2012). O grupo apresenta grande variação em tamanho, forma corporal e diversidade ecológica. A diferença de massa corporal entre as formas viventes varia entre cerca de $6 \mathrm{~g}$ (Micromys Dehne, 1841 e Delanymys Hayman, 1962) até mais de $60 \mathrm{~kg}$ (Hydrochoerus Brisson, 1762) (Hafner \& Hafner 1988), e alguns representantes fósseis do clado, como Phoberomys Kraglievich, 1926, Josephoartigasia Mones, 2007 e Phugatherium Ameghino, 1887, atingiram ou ultrapassaram as dimensões de grandes mamíferos sul-americanos viventes, como os tapires (Kraglievich 1941, Horovitz et al. 2006, Rinderknecht \& Blanco 2008).

A origem dos roedores é provavelmente laurásica (assim como os demais Boreoeutheria - vide Asher et al. 2009) e os táxons mais antigos são do Paleoceno final/Eoceno inicial (Hartenberger 1998). Todavia, estimativas baseadas em dados moleculares têm sugerido que o surgimento do grupo é bem mais antigo, tendo esse divergido dos demais eutérios possivelmente durante o Cretáceo médio (ver Honeycutt et al. 2007 e referências). Landry Jr. (1999) argumentou que as formas paleocênicas são morfologicamente muito especializadas, também sugerindo uma origem cretácica para o grupo. Porém, estudos recentemente publicados contestam as inferências de uma ori- gem mais antiga do que o início do Paleoceno (Wu et al. 2012, O’Leary et al. 2013). A definição filogenética proposta por Meng \& Wyss (2001) caracteriza os Rodentia como "grupo que inclui o ancestral comum mais recente de Mus Linnaeus, 1758 e todos os mamíferos mais próximos a ele do que com Lagomorpha e outros eutérios"; e Rodentiaformes seria o grupo que inclui "o ancestral comum mais recente entre Mus e Tribosphenomys Meng et al. 1994" (entretanto vide a posição filogenética de Tribosphenomys em O'Leary et al. (2013). Rodentia e Lagomorpha formam um grupo monofilético - Glires (Murphy et al. 2001a,b, Meng et al. 2003, O'Leary et al. 2013) (ver Meng \& Wyss 2005 para discussão sobre a monofilia de Glires), que por sua vez tem sido relacionado em filogenias propostas com base em dados moleculares com Primates, Scadentia e Dermoptera, formando o clado Euarchontoglires (ver Murphy et al. 2001a,b, Springer et al. 2004). A monofilia de Euarchontoglires tem sido corroborada em diversos trabalhos (vide Asher et al. 2009).

Dentro de Rodentia, esquemas de classificações baseados principalmente no sistema zigomassetérico e mandibular foram propostos antes do advento da sistemática filogenética (e.g. Brandt 1855, Tullberg 1899, Wood 1954, 1955, 1965; entre diversos outros). De acordo com Marivaux et al. (2004), basicamente os agrupamentos mais inclusivos dentro de Rodentia têm sido divididos em quatro propostas: (1) Baseado no sistema zigomassetérico (Sciuromorpha, Hystricomorpha e Myomorpha Brandt 1855 e Protogomorpha - Wood 1965); (2) Baseado no ângulo do processo angular relativo ao plano dos incisivos (Hystricognathi e Sciurognathi - Tullberg 1899); (3) padrões dentários (Pentalophodonta e Non-Pentalophodonta - Stehlin \& Schaub 1951); (4) Filogenias moleculares (e.g. Nedbal et al. 1996, Adkins et al. 2001; Debry \& Sagel, 2001, Montgelard et al. 2002, Huchon et al. 2002, Rowe et al. 2002; Honeycutt et al. 2007, Venimianova et al. 2007, Honeycutt 2009, Fabre et al. 2015).

Atualmente sabe-se que a história evolutiva dos clados dentro de Rodentia é mais complexa do 
que previamente suposto, pois ao longo da história evolutiva deste grupo surgiram diversas homoplasias que levaram à proposição de agrupamentos que recentemente não têm sido considerados monofiléticos (ver Hautier et al. 2015). Mais recentemente, grande avanço na compreensão das relações de parentesco entre as linhagens de Rodentia tem se dado por meio do uso de dados moleculares para estabelecer filogenias. Por exemplo, Huchon et al. (2000) reconheceram cinco principais linhagens: Pedidae, Myodonta, Gliridae, Sciuroidea e Ctenohystrica. Ctenohystrica, inclui os Hystricognathi mais os Diatomyidae e Ctenodacylidae, sendo que esse último era incluído em Sciurognathi. Desta forma, o último grupo citado não seria um grupo válido. Em 2002, Huchon e colaboradores reconheceram três linhagens principais: Ctenohystrica, Gliridae + Sciuroidea, e um clado "mouse-related" (Anomaluromorpha, Castoridae + Geomyoidea e Myodonta). Análises cladísticas de clados mais inclusivos de Rodentia baseados em caracteres morfológicos são menos comuns. Marivaux et al. (2004) utilizaram caracteres dentários de roedores paleógenos. Nesta análise, os autores reconheceram uma dicotomia na história evolutiva inicial do grupo, e propuseram duas principais linhagens: Ctenohystrica e Ischyromyiformes. De acordo com esses autores, as interpretações com base na morfologia seriam consistentes com os dados moleculares. Esses artigos constituem apenas alguns exemplos dos trabalhos que estão sendo desenvolvidos atualmente, sendo que aqui não se pretende abordar em detalhe as relações dentro de Rodentia, uma vez que esse tema está além do escopo do trabalho. Entretanto, informações estão disponíveis, além das referências supracitadas, em Rowe et al. (2002), Honeycutt et al. (2007), Venimianova et al. (2007), Honeycutt (2009). Uma ampla revisão sobre o tema está disponível em Cox \& Hautier (2015), e mais especificamente em Fabre et al. (2015), onde os autores compilam uma ampla variedade de dados, e demonstram a congruência entre os dados mole-

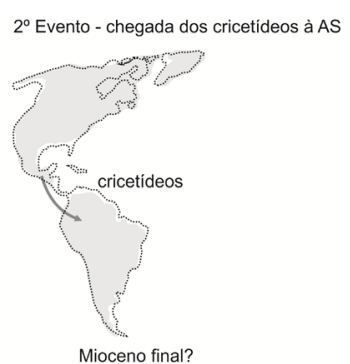

Mioceno final?

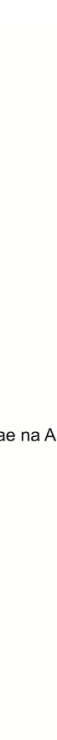

Pleistoceno final
Holoceno

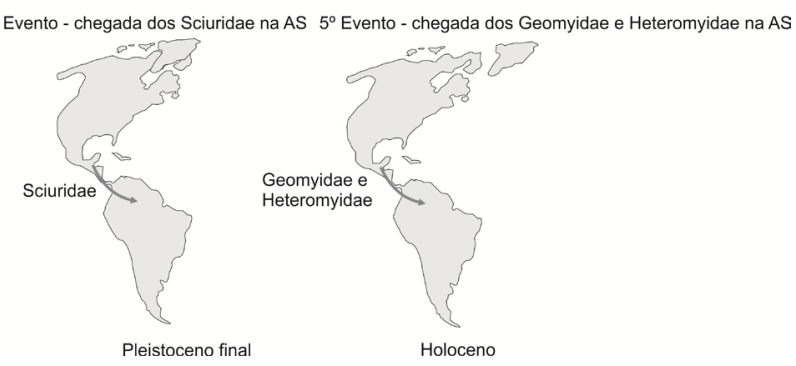

culares que corroboram a presença três grandes clados em Rodentia - Ctenohystrica mais os dois clados não nomeados formalmente - Squirrel-related e Mouse-Related.

Os roedores que habitam a América do Sul incluem cinco grupos (Caviomorpha, Sigmodontinae, Sciuridae, Heteromyidae e Geomyidae) que possuem origens filogenéticas e biogeográficas distintas (Fig. 2). Esta atual composição faunística foi modelada, em parte, graças ao Grande Intercâmbio Biótico Americano (GIBA), que promoveu a troca de faunas entre a região Neotropical (América do Sul - AS) e Holártica (América do Norte - AN e América Central - AC) devido ao soerguimento do Istmo do Panamá (e.g. Simpson 1980, Reig 1981, Woodburne et al. 2006, Woodburne 2010). Entretanto a história dos roedores sul-americanos é mais antiga, iniciando-se durante o Paleógeno.

Os primeiros a ingressarem na AS foram os roedores histricognatos (Ctenohystrica: Hystricognathi), provavelmente vindos da África, durante o Eoceno inicial/médio (Fig. 2), que deram origem aos Caviomorpha (evidências paleontológicas - e.g. Antoine et al. 2012, entre outros; e moleculares - e.g. Huchon \& Douzery 2001, Upham \& Patterson 2015, entre outros). No intervalo de tempo que precedeu a formação do istmo supracitado, os caviomorfos atingiram grande diversificação morfológica e ecológica, talvez não vista em nenhum grupo de roedores de outras partes do mundo. Antes mesmo do total soerguimento do istmo, iniciou-se o intercâmbio das faunas de roedores histricognatos sul-americanos e dos roedores de origem holárticas (Fig. 2). 
No caso dos imigrantes holárticos, os primeiros roedores a aparecerem em depósitos sul-americanos são os Cricetidae Sigmodontinae (Fig. 2). Esse clado apresentou intensa radiação adaptativa, e atualmente apresenta mais de 350 espécies viventes (Woods \& Kilpatrick 2005). O registro mais antigo do clado é datado para o final do Mioceno (SALMA Huayqueriense) (Verzi \& Montalvo 2008) ou Plioceno inicial (SALMA Montehermosense) (vide crítica em Prevosti \& Pardiñas 2009). Entretanto, Nasif et al. (2009) reportaram uma egagrópila do Mioceno final contendo um molariforme atribuído a um Sigmodontinae que pode corresponder à evidência mais antiga de um membro desse clado em nosso continente. Todavia, as formas do Neógeno estão restritas ao sul do continente, ao passo que registros nos depósitos do Norte da AS são ainda desconhecidos. Reig (1984) ressaltou que as formas pliocênicas (Chapadmalalense e Montehermosense) apresentam morfologia dentária muito derivada, sugerindo maior antiguidade do grupo neste continente. Estimativas com base em dados moleculares sugerem divergência anterior à idade dos mais antigos fósseis confirmados desses roedores. Parada et al. (2013) sugeriram que os Sigmodontinae se diferenciaram no Mioceno médio e que as linhagens que deram origem aos grupos menos inclusivos desse clado já estariam diversificados no Mioceno final. Leite et al. (2014) sugerem igualmente que a origem do grupo ocorreu durante o Mioceno médio/final (9-12 Ma).

No caso dos caviomorfos, após a formação do istmo, pelo menos dois grupos invadiram o continente norte-americano - Hydrochoerinae e Erethizontidae - representados em depósitos desta área geográfica (México e Estados Unidos) desde o final do Plioceno (Fig. 2), sendo que o primeiro sobreviveu até o final do Pleistoceno (atualmente restrito à AS) e o segundo ainda mantém um táxon vivente, Erethizon dorsatum (Linnaeus, 1758), que habita as florestas temperadas da AN (vide Marshall et al. 1982; Woodburne et al. 2006; Woodburne 2010). Na AC e AN os Hydrochoerinae são representados por Phugatherium Ameghino (1887) e Neochoerus Hay, 1926, que aparecem no registro fossilífero do Plioceno até o final do Pleistoceno (Hay 1926, Carranza-Castañeda \& Miller 1988, Vucetich et al. 2015a, Carranza-Castañeda 2016).

Os roedores Sciuridae não apresentam registro fossilífero antes do final do Pleistoceno (Fig. 2) (Pleistoceno Superior/Holoceno - Winge 1887, Castro \& Langer 2011). Atualmente existem duas "subfamílias" no continente: Sciurillinae, representada por Sciurillus Thomas, 1914, e Sciurinae, representada por Guerlinguetus Linnaeus, 1766. Os Heteromyidae e Geomyidae são roedores que só possuem formas viventes no Norte da AS, representando colonização mais recente do que os demais grupos (Woodburne et al. 2006) (Fig. 2). Assim, o registro fossilífero dos roedores que compõem a fauna sul-americana revela sucessivos episódios de colonização, especiação e extinção, que vão do Eoceno médio até o Holoceno (Fig. 2). Entre os grupos que chegaram ao nosso continente, os caviomorfos certamente são um clado com história evolutiva complexa e facinante de ser elucidada.

\section{Caviomorfos}

Caviomorpha é, como vimos, um grupo de roedores histricognatos sul-americanos (Upham \& Patterson 2015) (Fig. 3). A semelhança entre os caviomorfos e histricognatos africanos e a presença de fósseis de mandíbula histricognata da América do Norte (vide Wood 1972, 1973) levaram a várias hipóteses de origem e dispersão dos Caviomorpha durante as décadas de 1950-1980, sendo duas as principais: uma argumentando pela origem desse grupo a partir de formas norte-americanas (defendida principalmente pelos paleontólogos Albert E. Wood e Bryan Patterson); e outra, a partir de formas africanas (defendida principalmente pelos

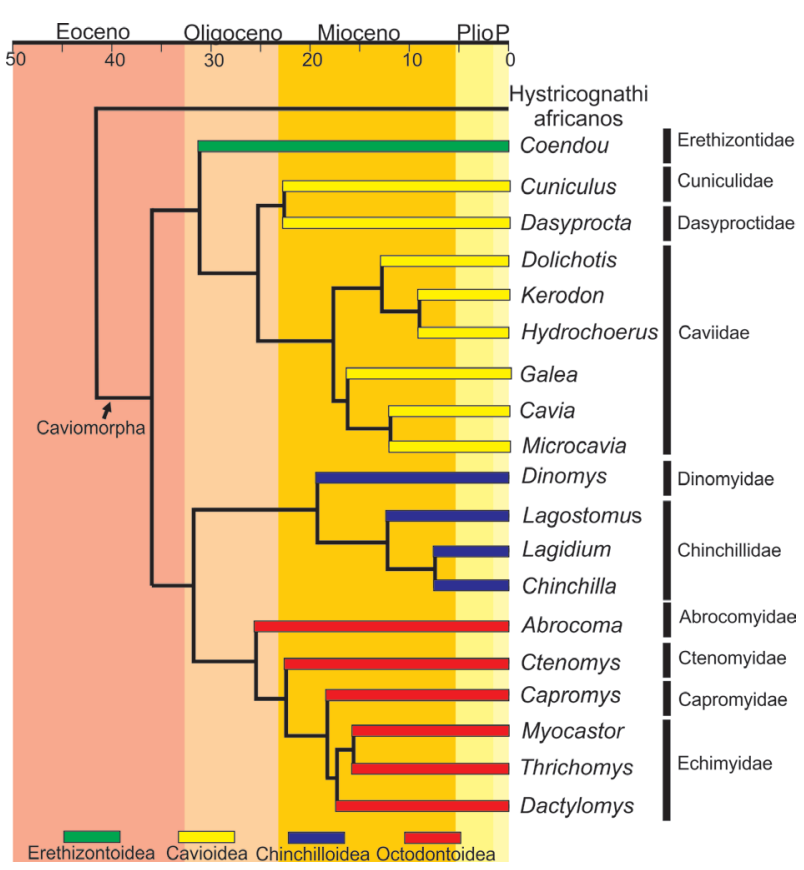

Figura 3. Filogenia simplificada dos Caviomorpha. Modificado de Upham \& Patterson (2015) 
paleontólogos René Lavocat e Robert Hoffstetter) (vide Cox \& Hautier 2015). Para mais informações sobre a discussão de origem dos caviomorfos consultar, por exemplo, Lavocat $(1969,1971)$, Hoffstetter $(1972,1975)$, Wood $(1972,1973)$, Wood \& Patterson (1959, 1970), Patterson \& Wood (1982). Atualmente a segunda hipótese é mais frequentemente assumida (e.g. Wyss et al. 1993, Huchon \& Douzery 2001, Martin 1994, 2005, Antoine et al. 2012, Upham \& Patterson).

Após o advento da utilização de dados moleculares para estabelecer as relações de parentesco entre os organismos, diversos trabalhos foram publicados sobre relações filogenéticas entre os caviomorfos e sobre o tempo de divergência dos grupos que formam esse clado (relógios moleculares) (e.g. Huchon \& Douzery 2001, Opazo 2005, Upham \& Patterson 2015). Entretanto, as relações filogenéticas de clados mais inclusivos em Caviomorpha ainda não são completamente estabelecidas no tocante aos grupos extintos, e grande parte dos sistematas ainda utiliza os agrupamentos taxonômicos tradicionais. Segundo Bertrand et al. (2012), o próprio nome Caviomorpha necessita de uma definição filogenética. Outro aspecto é que alguns grupos permanecem na mesma posição em análises morfológicas, moleculares e parasitológicas, enquanto outros são controversos.

Fósseis de roedores caviomorfos surgem a partir do Eoceno médio (Antoine et al. 2012), sendo mais provável que teriam ingressado no continente antes ou durante esse intervalo de tempo, uma vez que não há evidências de roedores em depósitos mais antigos com abundante diversidade e quantidade de pequenos mamíferos, como os depósitos de Rio Chico e Itaboraí (Hoffstetter 1975). Isso sugere que roedores ainda não estavam presentes, ou não se apresentavam amplamente distribuídos e diversificados durante a deposição sedimentar dessas localidades.

Até recentemente os primeiros registros de roedores sul-americanos eram provenientes da fauna de Tinguiririca no Chile, datada em torno de 31 milhões de anos (Tinguiririquense, Oligoceno inicial), de onde foi coletado um dentário atribuído a um Dasyproctidae (Wyss et al. 1993). Posteriormente, Flynn et al. (2003), em uma lista de táxons de Tinguiririca, além de Dasyproctidae, listaram também um fóssil de Chinchillidae. Esses fósseis apenas recentemente foram descritos como Andemys termasi ("Pan-Dasyproctidae") e Eoviscaccia frassinettii ("Pan-Chinchillidae") (Bertrand et al.
2012), respectivamente. Esta última espécie documenta o aparecimento mais antigo da hipsodontia em roedores caviomorfos.

Uma fauna de caviomorfos basais, proveniente de Santa Rosa no Peru, foi descrita por Frailey \& Campbell (2004). Baseados no "estágio evolutivo" dos táxons ali encontrados, os autores propuseram que essa fauna seria possivelmente do Eoceno final, entretanto, devido à ausência de datações absolutas, a idade é questionável. Além disso, de acordo com Vucetich et al. (2010a), a fauna poderia ter idade oligocênica.

A descoberta de novos fósseis provenientes $\mathrm{da}$ Amazônia peruana, talvez os mais importantes dos últimos anos para o estudo da origem dos roedores sul-americanos por Antoine et al. (2012), associados à datação absoluta de cerca de 41 milhões de anos, demonstrou que os caviomorfos já estavam presentes na América do Sul pelo menos durante o Eoceno médio. Os indivíduos compartem diversos caracteres com os histricognatos do Paleógeno da África, reforçando a ideia da ascendência africana para o grupo. Os dados estão de acordo com os relógios moleculares que estimam que a divergência dos Caviomorpha ocorreu entre 54 e 43 milhões de anos AP (Huchon \& Douzery 2001).

No modelo proposto por Vucetich et al. (1999), a história evolutiva dos caviomorfos foi marcada por dois grandes períodos de diversificação. A primeira radiação adaptativa ocorreu no início do Oligoceno. A partir desse momento, o registro fossilífero que era pouco diversificado torna-se abundante $\mathrm{e}$ diverso, e também é marcado pelo aparecimento das primeiras formas com dentes de crescimento contínuo. O segundo grande evento de diversificação ocorreu no Mioceno médio/final onde diversos grupos modernos tiveram suas primeiras aparições. Nas Antilhas, AC, ocorrem dois grupos de caviomorfos: os "Heptaxodontidae" - roedores extintos de afinidades filogenéticas incertas (vide Macphee 2011), - e Capromyidae, com representantes viventes, relacionados aos Echimyidae. Recentemente, fósseis de roedores, ainda que escassos, foram encontrados em depósitos oligocênicos de Porto Rico, confirmando uma colonização rápida desta área geográfica após a chegada dos caviomorfos na América do Sul (Vélez-Juarbe et al. 2014).

Embora o maior roedor tenha sido registrado em sedimentos plio-pleistocênicos (Rinderknecht \& Blanco 2008), é no final do Mioceno que os roedores caviomorfos apresentam sua maior diversidade de formas com grande massa corpórea, 


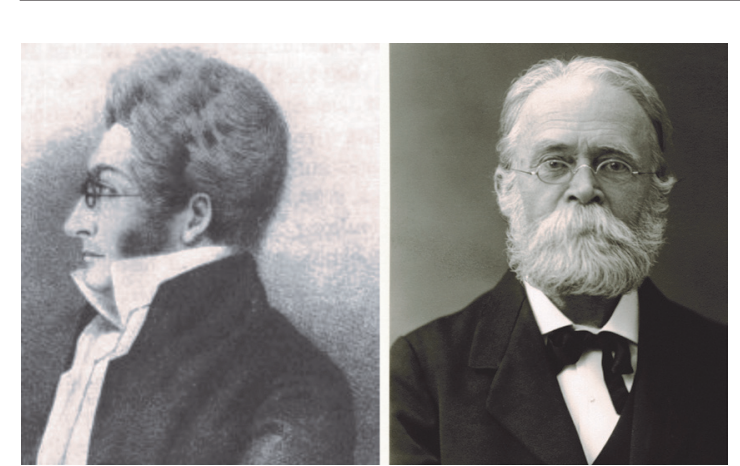

Figura 4. Os primeiros estudiosos de roedores fósseis do Brasil: Peter W. Lund e Herluf Winge, da esquerda para direita, respectivamente. Fonte: Natural History Museum of Denmark - Zoological Museum

fato observado principalmente em Dinomyidae e Neoepiblemidae. A partir do Plioceno, as formas de grande porte passam a declinar em diversidade e a composição taxonômica de Caviomorpha aos poucos vai tomando a forma atual (Vucetich et al. 2015b). Durante o Quaternário, as diferenças em relação à fauna atual são em sua maioria da ordem de distribuição geográfica, e não de diversidade ou morfologia (vide, por exemplo, Vucetich \& Verzi 1999, Ubilla 2008, Kerber et al. 2012a).

No Brasil, o estudo dos fósseis de roedores iniciou-se no século XIX com os trabalhos do naturalista dinamarquês Peter W. Lund (Fig. 4) (Lund 1837, 1839, 1840; vide Paula Couto 1950 para uma revisão desses trabalhos) sobre Lagoa Santa e posteriormente pela revisão de seus trabalhos pelo seu sucessor, o também dinamarquês Herluf Winge (Fig. 4) (Winge 1887). Após os trabalhos de Lund e Winge, houve um longo período praticamente sem publicações tratando sobre esse tema, salvo raras exceções (e.g. Patterson 1942). Carlos de Paula Couto, o maior expoente da paleomastozoologia brasileira do século XX, tratou especificamente sobre fósseis de roedores em poucos trabalhos (e.g. notas de rodapé em Paula Couto 1950, Paula Couto 1951, 1978a, 1983), comparado ao montante de publicações do autor. Somente a partir da segunda metade do século XX os estudos se tornaram mais frequentes, embora ainda bastante isolados.

Logo, o presente artigo trata sobre o registro fossilífero de roedores Cavimorpha no Brasil, estabelecendo o estado atual do conhecimento sobre a temática. Os registros apresentados na literatura são compilados na Tabela Suplementar $1^{2}$. O registro fossilífero de Caviomorpha do Brasil conta parte

2 Nota do editor: A partir desta edição, Terræ Didatica passou a publicar Informação Suplementar (IS), quando for necessário. 0 material IS é importante para completar ou concluir um documento mas não cabe nas versões online e impressa, por vários motivos.

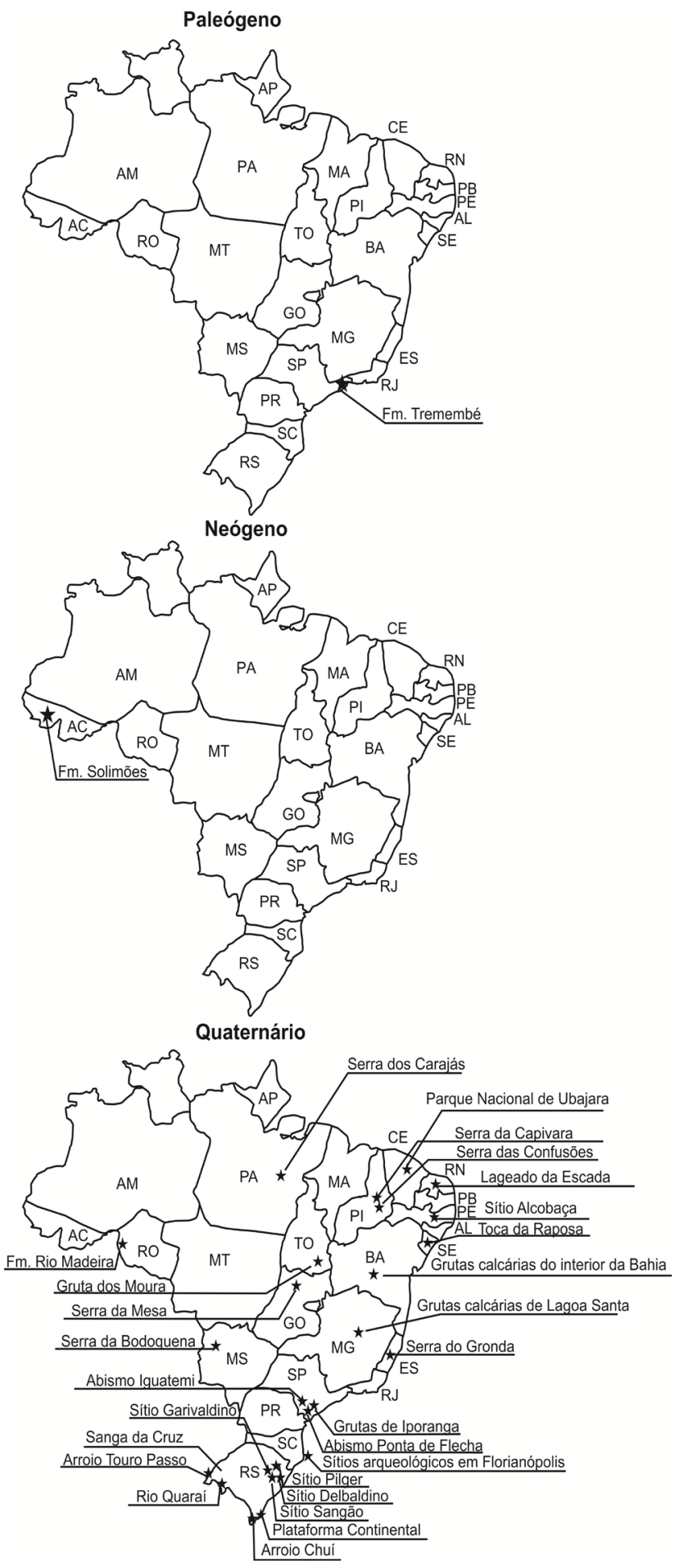

Figura 5. Principais localidades com fósseis de roedores do Brasil (vide Tabela 1). Estados: AC, Acre; AL, Alagoas; AM, Amazonas; AP, Amapá; CE, Ceará; ES, Espírito Santo; GO, Goiás; MG, Minas Gerais; MA; Maranhão; MS, Mato Grosso do Sul; MT, Mato Grosso; PA, Pará; PB, Paraíba; PI, Piauí; PE, Pernambuco; PR, Paraná; RJ, Rio de Janeiro; RN, Rio Grande do Norte; RO, Rondônia; RS, Rio Grande do Sul; RR; Roraima; SC, Santa Catarina; SE, Sergipe; SP, São Paulo; TO, Tocantins 
da história evolutiva dos grupos: Erethizontidae, Echimyidae, Ctenomyidae, Caviidae (incluindo Hydrochoerinae), Dasyproctidae, Cuniculidae, Dinomyidae e Neoepiblemidae. Os intervalos de tempo registrados com fósseis desses roedores são o Oligoceno final, Neógeno e Quaternário (Fig. 5). Abreviaturas: AC, América Central. AN, América do Norte. AS, América do Sul. SALMA South American Land Mammal Age. ZMK, Coleção paleontológica do Natural History Museum of Denmark - Zoological Museum, Copenhague, Dinamarca.

\section{Sistemática paleontológica}

Rodentia Bowdich, 1821

Ctenohystrica Huchon, Catzeflis, and Douzery, 2000

Hystricognathi Tullberg, 1899

Caviomorpha Wood \& Patterson (in Wood, 1955)

\section{Erethizontoidea Simpson, 1945}

Erethizontidae Thomas, 1897

\section{Gênero Coendou Lacépède, 1799}

\section{Distribuição temporal: Quaternário}

Comentários: Coendou, popularmente conhecido como porco-espinho ou ouriço, inclui diversas espécies de hábito arborícola amplamente distribuídas pelas regiões florestadas da América do Sul e Central (Emmons \& Feer 1997, Voss 2011). No Quaternário do Brasil, seu registro é escasso, restrito à região tropical, principalmente em Minas Gerais, Bahia e Piauí (Tabela Suplementar 1). Além de táxons não extintos, a partir de fósseis oriundos das cavernas de Lagoa Santa, Peter W. Lund (1839) descreveu a espécie extinta Coendou magnus (Lund, 1839) (Fig. 6), de proporções maiores do que àquelas de outros eretizontídeos viventes da AS, e
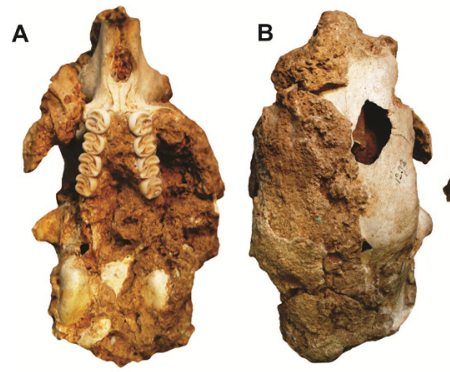

$c$

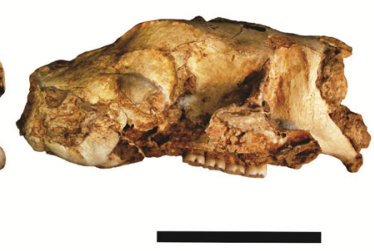

Figura 6. Crânio de Coendou magnus (ZMK 1/1845: 1292) em vista ventral $(A)$, dorsal $(B)$ e lateral $(C)$ proveniente de Lagoa Santa. Escala: $50 \mathrm{~mm}$ comparáveis aquelas de Erethizon dorsatum, o maior membro vivente de Erethizontidae. Esse táxon ainda carece de uma descrição anatômica comparada aos outros eretizontídeos, embora Ubilla (1996) e Sussman (2011) tenham tecido considerações a respeito da morfologia do dentário.

\section{Erethizontidae indet.}

Distribuição temporal: Neógeno

Comentários: No Brasil existem registros de eretizontídeos indeterminados do Neógeno da Formação Solimões ${ }^{3}$ (Frailey 1986, Campbell et al. 2006). Campbell et al. (2006) sugeriram similaridade desses espécimes com eretizontídeos do Mioceno médio da Colômbia.

\section{Pan-Octodontoidea Arnal \& Vucetich (2015)}

\section{†Sallamys? minutus Vucetich \& Ribeiro, 2003}

Distribuição temporal: Oligoceno final Comentários: O gênero Sallamys foi originalmente descrito a partir de fósseis das camadas oligocênicas de Salla, na Bolívia (Hoffstetter \& Lavocat 1970). No Brasil, uma espécie com afinidades a esse táxon foi descrita com base em um molariforme proveniente do Oligoceno da Formação Tremembé, Estado de São Paulo (Vucetich \& Ribeiro 2003) (Fig. 7). Arnal \& Vucetich (2015) incluíram Sallamys? minutus em Pan-Octodontoidea. Interessantemente, nessa análise Sallamys? minutus não se agrupou com Sallamys pascuali, a espécie-tipo do gênero, podendo assim, sugerir-se que o táxon da Formação Tremembé não corresponda a esse gênero.

\section{†Paulacoutomys paulista Vucetich et al. 1993}

Distribuição temporal: Oligoceno final Comentários: Paulacoutomys paulista foi descrito com base em um dentário esquerdo proveniente do Oligoceno da Formação Tremembé, Estado de São Paulo (Vucetich et al. 1993) (Fig. 7, 8). Candela \& Rasia (2012) consideraram esse táxon como um eretizontoideo. Mais recentemente, a análise de Arnal \& Vucetich (2015) considerou P. paulista como um Pan-Octodontoidea.

\footnotetext{
3 Ao longo do texto, nos referimos a idade da Formação Solimões como Neógeno. Entretanto, é importante frisar que recentemente Hsiou et al. (2017) reportaram datações que correspondem ao Tortoniano para dois afloramentos desta unidade sedimentar. Discussão sobre a biocrologia dos táxons ali encontrados está disponível em Cozzuol (2006), Latrubesse et al. (2007; 2010), Ribeiro et al. (2013) e Kerber et al. (2017a).
} 


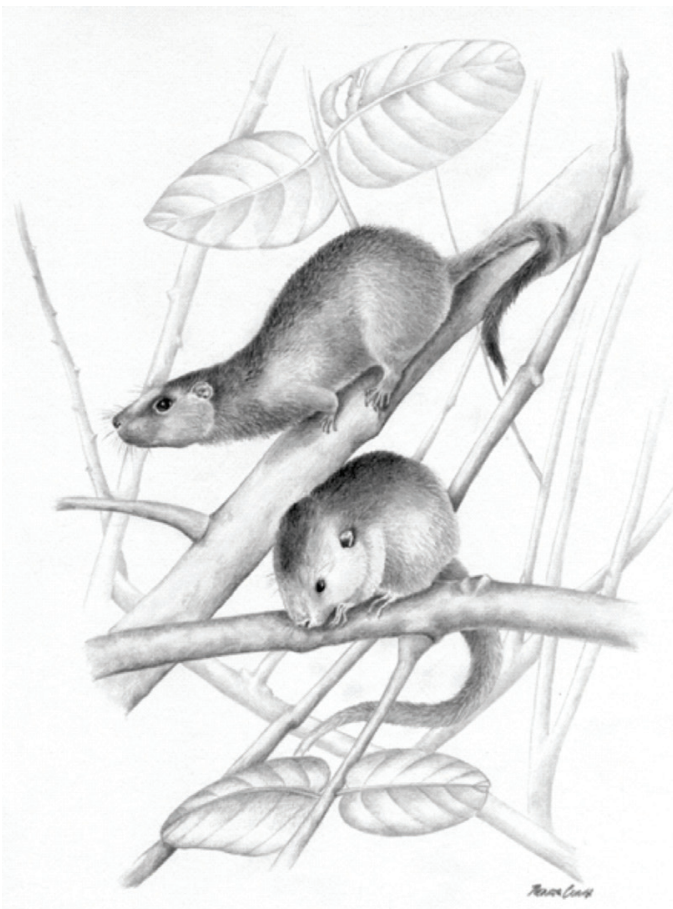

Figura 7. Reconstituição artística dos roedores Paulacoutomys paulista e ?Sallamys minutus do Oligoceno final da Formação Tremembé, Bacia de Taubaté, São Paulo. Ilustração por Renata Cunha

\section{Octodontoidea Simpson, 1945 \\ Echimyidae Gray, 1825}

\section{†Dicolpomys fossor Winge, 1887}

Distribuição temporal: Pleistoceno final

Comentários: Um interessante Echimyidae extinto do Brasil é Dicolpomys fossor (Fig. 9), descrito com base em fósseis do Quaternário de Minas Gerais (Winge 1887). Esse roedor é bastante peculiar, pois foi descrito originalmente como um Octodontidae devido à presença de dentes de contorno octogonal, e posteriormente incluído em Echimyidae (vide Hadler et al. 2008 para discussão). Uma análise filogenética desse táxon é necessária para testar sua posição em meio aos Echimyidae. Além de sua localidade tipo, D. fossor foi encontrado no Quaternário de São Paulo (Ameghino 1907) e Holoceno do Rio Grande do Sul (Hadler et al. 2008, 2016).

\section{Gênero Carterodon Waterhouse, 1848}

Distribuição temporal: Quaternário

Comentários: Carterodon sulcidens (Lund, 1841), a única espécie do gênero, possui uma distribuição bastante restrita, localizada na região central
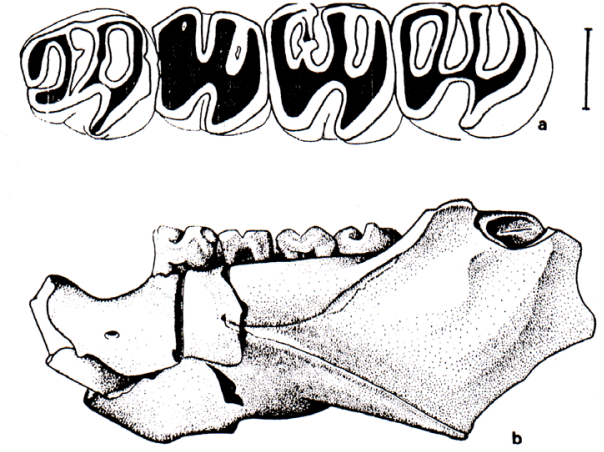

Figura 8. Paulacoutomys paulista do Oligoceno final da Formação Tremembé, em vista oclusal (A) e lateral (B). Extraído de Vucetich et al. (1993, fig. 2). Escala: $2 \mathrm{~mm}$

e sudeste do Brasil (Goiás, Minas Gerais e Bahia) (Reis \& Lacher 2008). Fósseis de C. sulcidens são reportados para a região tropical do Brasil (Tabela Suplementar 1), com destaque para um registro no Quaternário da Serra da Bodoquena, MS (Salles et al. 2006), que está fora da sua atual área de distribuição.

\section{Gênero Clyomys Thomas, 1916}

\section{Distribuição temporal: Quaternário}

Comentários: Clyomys possui uma espécie vivente, C. laticeps (Thomas, 1909), distribuída no sudeste e oeste do Brasil e leste do Paraguai (Bezerra \& Oliveira 2010). Entretanto, durante o Pleistoceno médio sua distribuição era bem maior, atingindo a Província de Buenos Aires (Vucetich et al. 1997). Devido à distribuição tropical de Clyomys, os autores relacionaram sua presença a um pulso climático mais quente durante o Pleistoceno médio. Fósseis de Clyomys foram encontrados em depósitos quaternários de Minas Gerais e Mato Grosso. Destaca-se uma espécie que se extinguiu durante o Holoceno do sul do Brasil (C. riograndensis Hadler et al. 2008) que foi descrita por Hadler et al. (2008), com base em material craniano e dentário.

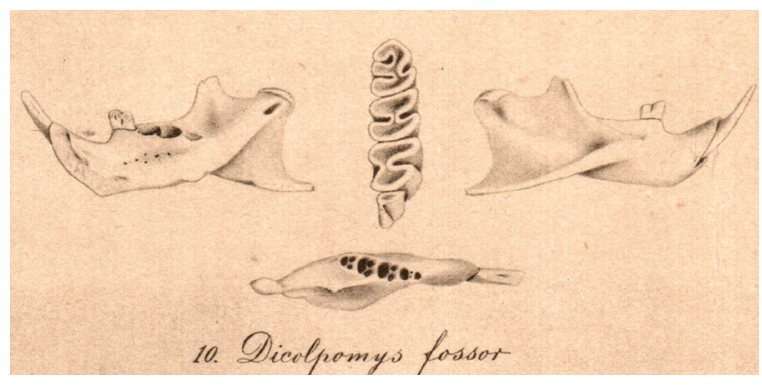

Figura 9. Dentário e série dentária inferior de Dicolpomys fossor. Extraído de Winge (1887, prancha VIII) 


\section{Gênero Euryzygomatomys Goeldi, 1901}

Distribuição temporal: Quaternário

Comentários: Euryzygomatomys possui uma única espécie vivente, E. spinosus (G. Fisher, 1814), que habita a Mata Atlântica do Brasil e uma pequena porção da Argentina (Catzeflis et al. 2008a). Winge (1887) descreveu uma espécie extinta, E. mordax Winge, 1887 proveniente do Quaternário de Lagoa Santa. Essa espécie foi posteriormente reportada por Hadler et al. (2008) para o Holoceno do Rio Grande do Sul. A presença desse táxon durante o Holoceno, assim como de outros roedores extintos, documenta a presença de extinções regionais nesse período.

\section{Gênero Trinomys Thomas, 1921}

Distribuição temporal: Quaternário

Comentários: Trinomys é um gênero altamente diversificado com mais de 10 espécies viventes (Woods \& Kilpatrick 2005). Essas espécies habitam principalmente a Mata Atlântica na região leste do Brasil. Existem apenas dois registros fósseis desse táxon, ambos na região tropical (Paula Couto 1950, Castro \& Langer 2011). Apesar do material proveniente de Lagoa Santa ter sido identificado em nível específico - T. setosus (Desmarest, 1821) - (vide Paula Couto 1950), ressalta-se que como existe uma grande diversidade de espécies recentes, para tal confirmação é necessário que se realize comparação de tais fósseis com uma ampla amostragem de espécimes recentes.

\section{Gênero Thrichomys Trouessart, 1880}

Distribuição temporal: Quaternário

Comentários: Thichomys é um equimídeo que habita a região norte e nordeste do Brasil, Paraguai e Bolívia (Reis \& Pessôa 2004). Possui hábitos escansoriais e no nordeste do Brasil é frequentemente encontrado habitando as áreas rochosas. No que concerne a diversidade do gênero, existe uma discussão na literatura sobre o número de espécies e ou subespécies. Abundante registro fossilífero do gênero é encontrado na região tropical do Brasil (Ferreira et al. 2012, Oliveira et al. 2013, Kerber et al. 2016a, Ferreira et al. 2016), embora identificados somente em nível genérico dado aos problemas taxonômicos das espécies atuais, bem como o estado fragmentário dos fósseis.

\section{Gênero Myocastor Kerr, 1792}

Distribuição temporal: Mioceno final Quaternário

Comentários: Myocastor coypus (Molina, 1782) é o único representante vivente do gênero. Esse animal é um herbívoro pastador e habita banhados e corpos d'água de baixa intensidade na Argentina, Chile, Bolívia, Paraguai e sul do Brasil (Woods et al. 1992). Atualmente sua distribuição está restrita somente à porção sul do continente, embora durante o Pleistoceno final-Holoceno tenha atingido até o nordeste do Brasil. No Brasil, existem diversos registros de Myocastor durante o Quaternário, os quais foram revisados por Kerber et al. (2014) e incluídos em M. coypus.

\section{Gênero Callistomys Emmons \& Vucetich, 1998}

Distribuição temporal: Quaternário

Comentários: Callistomys possui uma única espécie, C. pictus (Pictet, 1841), cuja distribuição está restrita a Mata Atlântica do Estado da Bahia (Moura $\&$ Da Fonseca 2008). Seu registro fossilífero também é pouco conhecido, com um único registro de um dentário de Callistomys sp. proveniente das grutas calcáreas de Lagoa Santa, MG (Emmons \& Vucetich 1998).

\section{Gênero Proechimys J. A. Allen, 1899}

Distribuição temporal: Quaternário

Comentários: Proechimys é um dos gêneros mais diversificados dentre os caviomofos viventes, com mais de 20 espécies distribuídas na região amazônica e cerrado (Patton \& Leite 2015). Fósseis não identificados em nível específico foram encontrados em depósitos do Holoceno do Pará (Toledo et al. 1999), Pleistoceno Superior de Tocantins (Ferreira et al. 2016) e Quaternário de Goiás (Salles et al. 1999).

\section{Gênero Dactylomys Saint-Hilaire, 1838}

Distribuição temporal: Quaternário

Comentários: Dactylomys habita a região amazônica do norte da América do Sul e é representado por três espécies: D. peruanus J.A. Allen, 1920, D. boliviensis Anthony, 1820, D. dactylinus (Desmarest, 1817) sendo as duas últimas registradas em território brasileiro (Woods \& Kilpatrick 2005). O único registro de fósseis de $D$. dactylinus é proveniente de um depósito do Holoceno da Serra dos Carajas, PA (Toledo et al. 1999). 


\section{Gênero Kannabateomys Jentink, 1891}

Distribuição temporal: Quaternário

Comentários: Kannabateomys amblyonyx (Wagner, 1845) é a única espécie do gênero e distribui-se pelo nordeste da Argentina, leste do Paraguai e leste e sul do Brasil (Catzeflis et al. 2008b). K. amblyonyx é reportado como fóssil para os estados de São Paulo e Minas Gerais (Tabela Suplementar 1).

\section{Gênero Echimys Cuvier, 1809}

Distribuição temporal: Quaternário

Comentários: Echimys possui quatro espécies viventes que habitam a região amazônica do norte da América do Sul (Catzeflis \& Patton 2008, Percequillo \& Patton 2008, Tirira \& Solari 2008). Possui um único registro de fóssil (Echimys sp.) no Holoceno da Serra dos Carajás, PA (Toledo et al. 1999).

\section{Gênero Phyllomys Lund, 1839}

\section{Distribuição temporal: Quaternário}

Comentários: Phyllomys inclui equimídeos arborícolas endêmicos da Mata Atlântica, cuja distribuição vai do Ceará até o Rio Grande do Sul (Moojen 1952, Leite 2003). Phyllomys é bastante diverso, com mais de 10 espécies viventes (Emmons et al. 2002). Fósseis atribuídos a Phyllomys sp. foram encontrados em depósitos do Quaternário de Minas Gerais, Holoceno do Rio Grande do Sul, Pernambuco e Piauí (Emmons et al. 2002, Hadler et al. 2008, Ferreira et al. 2012, Kerber et al. 2016a). A identificação taxonômica em nível específico desses fósseis não é determinada devido ao seu estado fragmentário. Emmons et al. (2002) ressaltaram esta problemática quando propuseram que entre os fósseis provenientes do Quaternário de Lagoa Santa há pelo menos outras duas unidades morfológicas que podem, ou não, pertencer às formas viventes.

\section{Gênero Makalata Husson, 1978}

Distribuição temporal: Quaternário

Comentários: Makalata inclui pelo menos quatro espécies de hábitos arborícolas que atualmente habitam a porção amazônica da América do Sul (Patton et al. 2008a, b, c, Zeballos et al. 2008). Seu registro como fóssil se deu apenas recentemente quando Ferreira et al. (2016) reportaram dentes isolados provenientes do Pleistoceno Superior de Tocantins.

\section{Echimyidae indet.}

Distribuição temporal: Neógeno

Comentários: Em camadas do Néogeno da Formação Solimões, o registro de Echimyidae é escasso, representado exclusivamente por molariformes de "Eumysopinae" indet. e Echimyidae indet. (Frailey 1986, Sant'Anna-Filho 1994, Campbell et al. 2006).

\section{Ctenomyidae Lesson, 1842}

\section{Gênero Ctenomys Blainville, 1826}

\section{Distribuição temporal: Quaternário}

Comentários: Ctenomys, o tuco-tuco, é o único gênero com representantes viventes dos Ctenomyidae. O táxon possui modo de vida subterrâneo e é extremente diversificado. Fósseis desse grupo estão representados por fragmentos cranianos e dentários atribuídos a Ctenomys sp. provenientes do Holoceno do Rio Grande do Sul (Hadler et al. 2008).

\section{Cavioidea Fisher de Waldheim, 1817}

Generos †Eoincamys Frailey \& Campbell, 2004 e †Eobranisamys Frailey \& Campbell, 2004

Distribuição temporal: Paleógeno

Comentários: Eoincamys e Eobranisamys foram descritos a partir de fósseis provenientes do Eoceno-Oligoceno de Santa Rosa no Peru e incluídos em Dasyproctidae $\left(=\right.$ Agoutidae $^{4}$ ) por Frailey e Campbell (2004). Mais tarde foram considerados como Caviomorpha incertae sedis por Vucetich et al. (2015b). Kerber et al. (2017a), apresentaram dentes isolados coletados ao longo do Rio Juruá, Acre, que possuem relação com tais táxons. Entretanto, o contexto estratigráfico em que esses roedores têm sido encontrados na região amazônica deve ser melhor explorado, uma vez que os espécimes reportados por esses autores foram encontrados fora das camadas originais de deposição.

\section{Caviidae Fisher de Waldheim, 1817}

\section{Gênero Cavia Pallas, 1766}

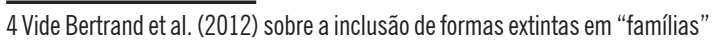
que foram propostas com base em táxons com representantes viventes. 
Distribuição temporal: Quaternário

Comentários: Conhecidos popularmente como preás ou porquinhos-da-índia, os representantes do gênero Cavia são distribuídos em diversas espécies que ocupam a maior parte da América do Sul. No Brasil, duas espécies extintas de Cavia foram descritas a partir de fósseis do Quaternário de Lagoa Santa: Cavia vates Winge, 1887 (Fig. 10) e Cavia lamingnae Locks \& Montenegro, 1985 (Fig. 11). A ilustração em Winge (1887) de C. vates (Fig. 10) sugere que esse táxon é distinto de $C$. aperea pela ausência de um flexo bem desenvolvido no segundo prisma e prismas menos comprimidos mesiodistalmente. A região mais anterior da fossa mesopterigoide é ampla, similar a Cavia, distinto de Galea spixii (Wagler, 1831) onde há um ângulo mais agudo. Cavia lamingnae proveniente de Lagoa Santa é, segundo Locks \& Montenegro (1985), distinto de C. vates. Ambas as espécies extintas necessitam de uma revisão e comparação com as outras espécies do gênero. No sul do Brasil Cavia aperea Erxleben, 1777 e Cavia magna Ximenes, 1980 foram registradas para o Holoceno (Hadler et al. 2008).

\section{Gênero Galea Meyen, 1832}

\section{Distribuição temporal: Quaternário}

Comentários: Galea é um pequeno roedor cursorial que habita as áreas abertas da América do Sul. Embora apresente um cenário taxonômico complexo (Bezerra 2008), considera-se que Galea possua cinco espécies de distribuição disjunta, com um grupo habitando a Argentina, Bolívia, Peru e oeste do Paraguai (G. musteloides Meyen, 1932, G. flavidens (Brandt, 1835), G. monasterensis Solmsdorff, Kock, Hohoff \& Sachser, 2004, G. comes Thomas, 1919) e outro habitando a porção norte de nordeste do Brasil (G. spixii (Wagler, 1831)) (entretanto, ver Dunnum \& Bravo 2010; Ubilla \& Rinderknecht 2014). Espécies extintas incluem G. ortodonta Ubilla \& Rinderknecht, 2001 do Pleistoceno do Uruguai e Bolívia, e G. tixiensis Quintana, 2001 do Pleistoceno-Holoceno da Província de Buenos Aires.

Abundante registro fossilífero de Galea é encontrado no nordeste do Brasil (Tabela 1). No espaço que separa os grupos supracitados, foram encontrados fósseis deste roedor, indicando uma distribuição mais ampla no passado (Ubilla \& Rinderknecht 2001, Kerber et al. 2011a, Francia et al. 2012). Esta área inclui a porção sul do Brasil, onde um dentário foi reportado por Kerber et al. (2011a) proveniente do Arroio Touro Passo (Pleistoceno

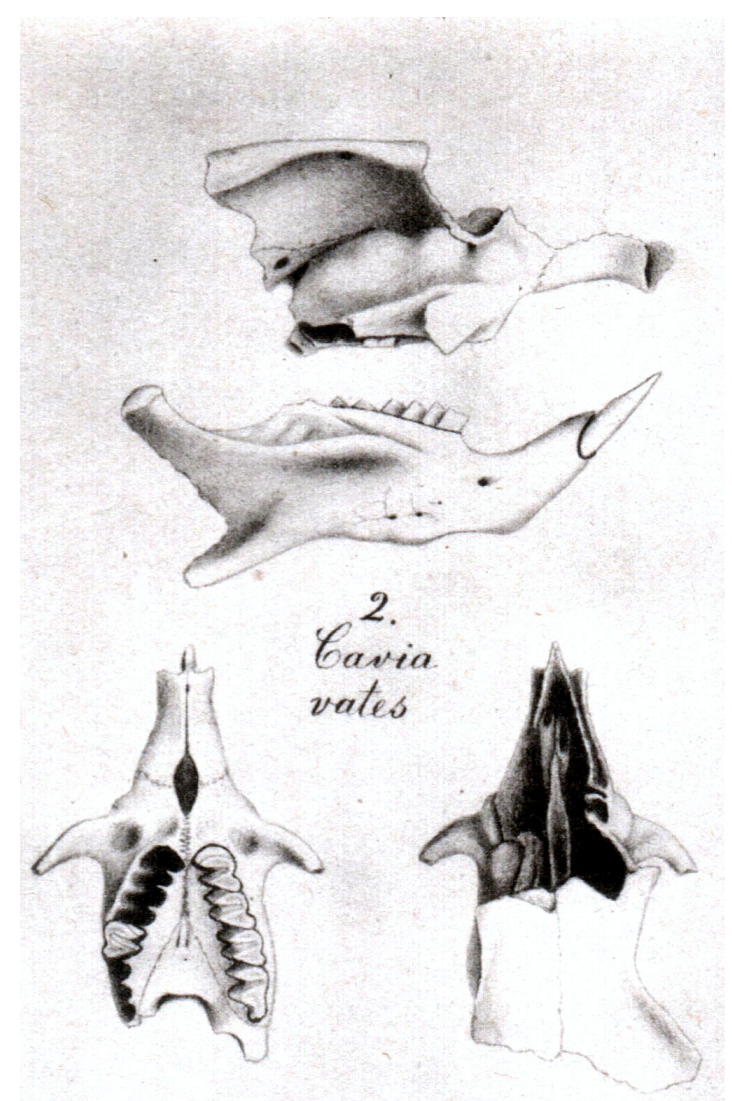

Figura 10. Crânio e dentário de Cavia vates. Extraído de Winge (1887, prancha VII)

Superior). Futuros testes paleobiogeográficos utilizando esses registros fora de sua atual área de distribuição podem ser elucidativos na interpretação dos fatores que levaram à segregação desses dois grupos.

Gênero Microcavia Gervais \& Ameghino, 1880 Distribuição temporal: Quaternário

Comentários: O gênero Microcavia é composto por

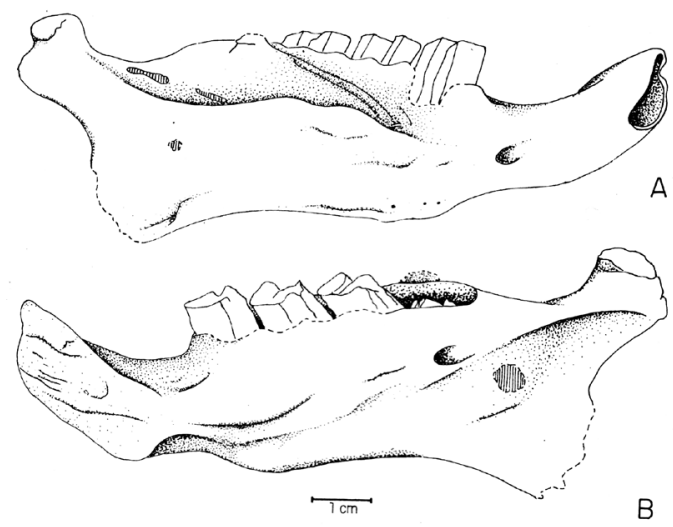

Figura 11. Dentário direito de Cavia lagminae. Extraído de Locks \& Montenegro (1985, fig. 4) 
três espécies que habitam atualmente a Argentina e sul da Bolívia (Tognelli et al. 2001, Wilson \& Reeder 2005). No Brasil, há um único registro atribuído a Microcavia sp. proveniente do Pleistoceno Superior do Arroio Chuí, RS (Ubilla et al. 2008). Esse roedor é atualmente associado a ambientes áridos, sendo que sua presença em camadas fossilíferas do Arroio Chuí foi interpretada pelos autores como indicativa de climas mais secos durante o tempo de deposição desta unidade sedimentar.

\section{Dolichotinae Pocock, 1922}

Distribuição temporal: Mioceno médio ao Quaternário

Comentários: Os Dolichotinae estão representados por um gênero com representantes viventes incluídos em duas espécies: Dolichotis patagonum (Zimmermann, 1780) e D. salinicola (Burmeister, 1876). Ambos são roedores cursoriais de grande porte em relação aos demais caviídeos e possuem distribuição restrita a ambientes áridos e semiáridos da Argentina, Paraguai e sul da Bolívia (Einsenberg \& Redford 1999, Campos et al. 2001). No Brasil, existem registros de um pré-molar inferior de Dolichotinae indet. do Neógeno da Formação Solimões (Kerber et al. 2017a), de um pré-molar superior atribuído a Dolichotinae indet. que foi reportado para a plataforma continental do RS (Rodrigues \& Ferigolo 2004), e de um molariforme proveniente do Arroio Chuí (Kerber et al. 2011b). Esses últimos dois registros demonstram a maior distribuição desse grupo de roedores durante o Pleistoceno.

\section{Hydrochoerinae (Gray, 1825) Gill, 1872}

\section{Gênero Kerodon F. Cuvier, 1825}

\section{Distribuição temporal: Quaternário}

Comentários: Kerodon, conhecido popularmente como mocó, atualmente habita a região tropical do Brasil. Apresenta duas espécies: K. rupestris F. Cuvier, 1825 distribuída na porção nordeste e parte da região sudeste; e K. acrobata Moojen, Locks \& Langguth, 1997, restrita ao Estado de Goiás (Moojen et al. 1997). Kerodon foi considerado um Caviinae em trabalhos taxonômicos e análises cladísticas (e.g. Quintana 1998). Entretanto, novos trabalhos usando dados moleculares (Rowe \& Honeycutt 2002) e morfológicos (incluindo dados paleontológicos) (Pérez 2010, Vucetich et al. 2012), o tem considerado como mais proximamente relacionado aos Hydrochoerinae.

O registro fossilífero de Kerodon rupestris é amplamente conhecido no nordeste do Brasil (Tabela Suplementar 1). Registros fora de sua atual área de distribuição são ainda desconhecidos.

\section{Gênero †Caviodon Ameghino, 1885}

Distribuição temporal: Neógeno

Comentários: Frailey (1986) descreveu fósseis atribuídos à Cardiomyinae provenientes do Rio Acre (Formação Solimões, Neógeno). Porém, de acordo com Vucetich et al. (2010b), esses materiais são possivelmente atribuídos a cavídeos e neoepiblemideos. Kerber et al. (2017a) reportaram material de Caviodon sp. proveniente do Rio Acre, sendo este o primeiro registro confirmado de um Cardiomyinae no Neógeno do Brasil.

\section{Gênero †Cardiatherium Ameghino, 1883}

\section{Distribuição temporal: Neógeno}

Comentários: Cardiatherium inclui algumas das capivaras mais antigas, que datam do final do Mioceno. Fósseis desse gênero têm sido encontrados principalmente na Argentina, mas também no Uruguai, Venezuela e Brasil (Deschamps et al. 2013). No Brasil há registros em depósitos do Neógeno (Formação Solimões), representados por molariformes isolados de Cardiatherium (=Kiyutherium), porções mandibulares e uma porção palatal (Frailey 1986, Kerber et al. 2017a), e fragmentos de dentes de um Hydrochoerinae indeterminado (Sant'Anna-Filho 1994).

\section{Gênero Hydrochoerus Brisson, 1762}

Distribuição temporal: Quaternário

Comentários: Hydrochoerus é considerado o maior roedor vivente e é representado por duas espécies viventes, Hydrochoerus hydrochaeris (Linnaeus, 1766), cuja distribuição cobre grande parte da América do Sul, excluindo áreas onde a água é um fator limitante, como os Andes, a Patagônia e a Caatinga no nordeste brasileiro; e Hydrochoerus ishtmius Goldman, 1912 que se distribui ao norte da América do Sul e sul da América Central (Mones \& Ojasti 1986). No Brasil, fósseis de Hydrochoerus hydrochaeris têm sido encontrados em depósitos do Quaternário da região sul e nordeste do Brasil (Tabela 1). Embora a espécie vivente também tenha sido citada para as cavernas de Lagoa Santa (Winge 1887), os fósseis 
depositados no ZMK referentes a esse táxon, são bastante fragmentários. Alguns espécimes apresentam menor tamanho do que Hydrochoerus, podendo corresponder a espécimes juvenis desse táxon ou ainda de alguma espécie de Neochoerus (Kerber et al. 2016a).

\section{Gênero †Neochoerus Hay, 1926}

Distribuição temporal: Quaternário

Comentários: Neochoerus é uma capivara extinta com espécies similares as formas atuais do gênero Hydrochoerus. Entretanto tais espécies apresentam maior tamanho e maior número de prismas no M3. Esse gênero possui registro fossilífero durante o Pleistoceno, sendo extinto ao final desse período. De acordo com Mones (1991), quatro espécies de Neochoerus são referidas para América do Sul (N. sulcidens (Lund, 1839), N. tarijensis (Ameghino, 1902), N. fontanai Rusconi, 1933 e N. aesopi Leidy, 1853). Porém, esta diversidade pode estar superestimada, uma vez que as diagnoses são baseadas em caracteres pouco informativos (e.g. pequena variação de tamanho). A exemplo das revisões de hidrochoerideos miocênicos (Vucetich et al. 2005, Deschamps et al. 2007), uma revisão dos táxons quaternários poderá, provavelmente, sinonimizar alguns táxons.

No Brasil o único táxon registrado é Neochoerus sulcidens, descrito por Peter Lund (1839) (Fig. 12) e posteriormente revisado por Mones (1991). N. sulcidens é também reportado para Minas Gerais (Quaternário), Bahia (Quaternário) e Rondônia (Pleistoceno Superior) (Mones 1991, Cartelle 1994, 1999, Cozzuol et al. 2006, Lessa et al. 2008).

\section{Dasyproctidae Smith, 1842}

\section{Gênero Dasyprocta Illiger, 1811}

\section{Distribuição temporal: Quaternário}

Comentários: Dasyprocta apresenta diversas espécies que se distribuem por toda a porção florestada da AS e AC. Iack-Ximenes (1999) realizou uma revisão taxonômica dos táxons que ocorrem no Brasil. Porém, os caracteres utilizados foram na sua maioria baseados na pelagem, o que não fornece informações que possam ser utilizadas em uma análise paleontológica. Dessa forma, a menos que se obtenha uma grande amostra comparativa, a idenficação em nível específico de
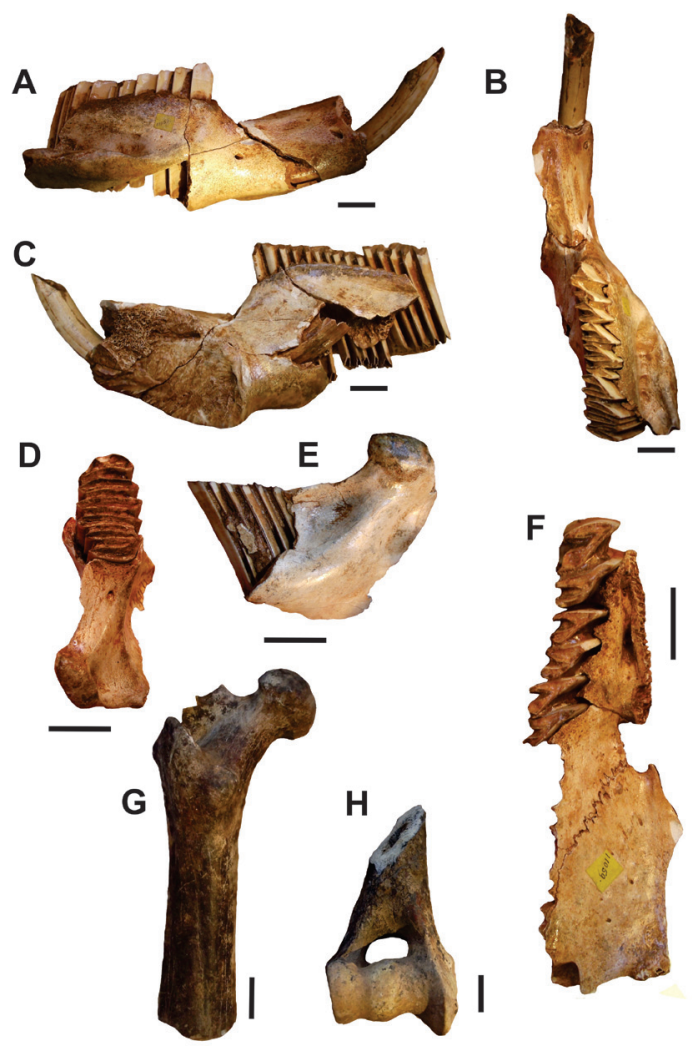

Figura 12. Fósseis de Neochoerus sulcidens provenientes de Lagoa Santa. A-C dentário direito (ZMK 1/1845:11055 - Lectótipo) em vista lateral (A), oclusal (B) e medial (C); D-E, fragmento de dentário esquerdo (ZMK 1/1845:2054) em vista oclusal (D) e lateral (E); F, porção palatal direita (ZMK 1/1845:11059), em vista oclusal; G, fêmur esquerdo (ZMK 1/1845:5744) em vista posterior; $\mathrm{H}$, extremidade distal de úmero direito ( $Z M K$ 1/1845:4899), em vista anterior. Escalas: $20 \mathrm{~mm}$. Fotos do autor

espécimes fósseis pode ser dificultosa. De acordo com a revisão de Iack-Ximenes (1999), no Brasil são reconhecidas as seguintes espécies viventes de Dasyprocta: D. aurea Cope, 1889, D. azarae Lichtenstein, 1823, D. catrinae (Thomas, 1917), D. fuliginosa Wagler, 1832, D. croconota Wagler, 1831, D. leporina (Linneaus, 1758), D. nigriclunis Osgood, 1916, D. prymnolopha Wagler, 1841 e D. aguti (Linnaeus, 1766). Entretanto, na lista taxonômica de Woods \& Kilpatrick (2005), D. aurea, D. catrinae e $D$. aguti são sinônimos de $D$. azarae; $D$. nigriclunis é sinônimo de $D$. prymnolopha; e $D$. croconota é uma subespécie de D. leporina.

No Brasil, há registros de fósseis de Dasyproctidae indet. em camadas do Neógeno da Formação Solimões (Sant'Anna-Filho 1994). 
Vucetich \& Verzi (2002) sugeriram que esse material talvez possa ser atribuído a Dasyprocta ou uma forma relacionada. No Quaternário há registros de Dasyprocta em camadas do Pleistoceno Superior/ Holoceno de Minas Gerais (Winge 1887) e Bahia (Lessa et al. 2008. Lund (1837) criou o táxon $D$. capreolus. Entretanto, de acordo com Paula Couto (1950, nota de rodapé 144, pg. 168), a validade desse táxon é muito duvidosa, uma vez que foi fundada com base em uma tíbia - de tamanho maior do que a dos táxons viventes. A determinação específica dos fósseis de dasiproctídeos do Quaternário é bastante complexa em virtude da ausência de revisões das espécies viventes baseadas em caracteres osteodentários.

\section{Cuniculidae Miller \& Gidley, 1918 \\ Gênero Cuniculus Brisson, 1762}

Distribuição temporal: Quaternário

Comentários: Cuniculus inclui duas espécies viventes, C. taczanowskii (Stolzmann, 1865), que habita uma porção da região andina, e C. paca (Linnaeus, 1766), distribuída pela maioria das áreas florestadas da América do Sul (Pérez 1992). O registro fossilífero desse grupo é pouco estudado e praticamente restrito ao Quaternário da região tropical do Brasil. Em 1837, Lund identificou, pela primeira vez, remanescentes fósseis de pacas que foram atribuídos a uma espécie distinta de Cuniculus paca, a qual foi nomeada $C$. rugiceps (Lund, 1837). Tal táxon diferenciava-se por seu tamanho, bem maior do que os indivíduos mais velhos de C. paca, e pela presença de rugosidades mais marcadas no crânio. Essa espécie possuiria também rugosidades no atlas. Em uma obra subsequente, Lund (1839) (vide Paula Couto 1950 , p. 169-170), mencionou novos fósseis de pacas; parte desses correspondentes à supracitada espécie extinta (novamente ressaltando sua maior robustez); parte correspondente a uma nova espécie - C. laticeps (Lund, 1839) - cuja porção posterior do arco zigomática projetava-se mais lateralmente, dando um aspecto mais achatado ao crânio (vide Paula Couto 1950, p. 169); e parte correspondendo a um terceiro táxon - C. major (Lund, 1839) - com maiores dimensões do que as demais espécies - "igualando a uma capivara" (Paula Couto 1950, pg. 170). Lund (1839) não mencionou o tamanho de C. laticeps. Em um suplemento daquele trabalho (Paula Couto 1950, p. 205), Lund (1839) sinonimizou as duas espécies de menor tamanho $-C$. rugiceps e C. laticeps, designando o último táxon como válido. $\mathrm{Na}$ revisão de Winge (1887), esse autor as considerou como subespécies de C. paca. Rusconi (1933) considerou a validade de C. major. Recentemente, com base em novos fósseis coletados com contexto estratigráfico, e na discussão acima citada, Mayer et al. (2016) consideraram que C. rugiceps é o nome válido para a paca extinta do Quaternário do Brasil.

\section{Chinchilloidea Kraglievich, 1940 \\ Chinchillidae Bennet, 1833}

\section{Gênero Lagostomus Brookes, 1828}

\section{Distribuição temporal: Quaternário}

Comentários: Lagostomus, conhecido como "vizcacha", é um roedor que habita atualmente as planícies do centro da Argentina, sul da Bolívia e oeste do Paraguai (Jackson et al. 1996 e referências). O gênero é representado por somente uma espécie vivente, L. maximus (Desmarest, 1817). O dimorfismo sexual no tamanho de Lagostomus é bastante acentuado (Einsenbeg \& Redford 1999). Esse táxon geralmente habita áreas abertas com vegetação campestre ou arbustiva, frequentemente com pouca chuva, e possui hábitos coloniais e escavadores (Einsenberg \& Redford 1999).

Até recentemente não haviam registros confirmados desse táxon no Brasil, bem como de Chinchillidae. Lund (1841) havia descrito o Lagostominae Lagostomus brasiliensis proveniente de Lagoa Santa, entretanto, a posterior revisão dos roedores desta região por Winge (1887) não confirmou a presença desse táxon. Além do mais, as características apresentadas na ilustração original não correspondem ao gênero Lagostomus. $\mathrm{O}$ único registro confirmado de um Chinchillidae no Brasil provém de sedimentos do Pleistoceno Superior do Rio Grande do Sul, Arroio Chuí, Santa Vitória do Palmar, onde um dentário de Lagostomus cf. $L$. maximus foi encontrado (Kerber et al. 2011b).

\section{Dinomyidae Alston, 1876}

\section{Gênero †Potamarchus Burmeister, 1855}

Distribuição temporal: Neógeno 
Comentários: Potamarchus é um Dinomyidae de molariformes proto-hipsodontes que foi originalmente descrito a partir de fósseis provenientes da Formação Ituzaingó, Mioceno Superior de Entre Rios na Argentina (Burmeister 1885, Ameghino 1898). Duas espécies foram propostas: P. murinus Burmeister, 1885 e $P$. sigmodon Ameghino, 1881. No Neógeno do Acre, ambas as espécies foram citadas (Frailey, 1986; Sant'Anna-Filho (1994), e posteriormente Kerber et al. (2016b) reportaram um novo fóssil de $P$. murinus e descreveram uma nova espécie - Potamarchus adamiae - proveniente de uma localidade no Rio Juruá (Figs. 13, 15).

\section{†Pseudopotamarchus villanuevai Kerber et al. 2016}

Distribuição temporal: Neógeno

Comentários: Kerber et al. (2016b) descreveram um novo gênero e espécie de Potamarchinae Neógeno da Formação Solimões, Pseudopotamarchus villanuevai, o qual é ainda pouco conhecido. Esse táxon guarda relação com Potamarchinae e apresenta uma incisura na face anterior da raiz ventral do processo zigomático do maxilar, não presente em outros membros desse grupo.

\section{†Ferigolomys pacarana Kerber et al. 2017b}

Distribuição temporal: Neógeno

Comentários: Um novo roedor foi recentemente descrito baseado em um palato com molariformes provenientes da localidade Niterói, Rio Acre (Neógeno) (Kerber et al. 2017b) (Fig. 14). Esta unidade taxonômica é reconhecida com base na combinação de caracteres que incluem dentes proto-hipsodontes, pentalofodontes, esmalte que contorna os lofos de espessura uniforme e presença de um sulco na lateral da maxila.

\section{Gênero † Drytomomys Anthony, 1922}

Distribuição temporal: Neógeno

Comentários: O gênero Drytomomys possui uma história taxonômica bastante confusa, sendo necessária a revisão desse táxon, principalmente no que concerne aos espécimes provenientes do Mioceno médio da Colômbia (vide Walton 1997). Drytomomys aequatorialis foi originalmente descrito com base em crânio e mandíbula de um depósito,

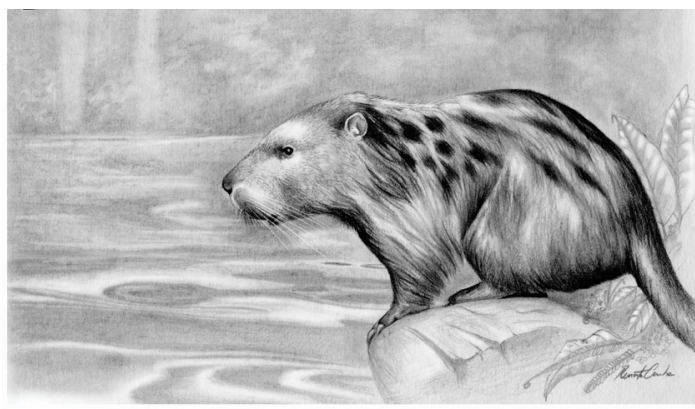

Fig. 13. Reconstituição artística de Potamarchus adamiae. Ilustração por Renata Cunha

cuja idade é desconhecida, do Equador (Anthony 1922). Posteriormente, Fields (1957) descreveu novos materiais provenientes de La Venta, Mioceno médio da Colômbia com afinidade a esse táxon, mas sinonimizou Drytomomys a Olenopsis Ameghino, 1899 (um táxon descrito com base em fósseis do Mioceno médio da Argentina). Walton (1997) considerou que os fósseis colombianos não eram pertencentes a espécie descrita por Anthony (1922), sendo que deveriam ser futuramente renomeados em duas espécies (Olenopsis sp. large e Olenopsis sp. small). Candela \& Nasif (2006) revalidaram o gênero Drytomomys, mas salientaram a necessidade de uma revisão taxonômica destas formas do Neógeno do norte da América do Sul. No Brasil, um espécime atribuído a Drytomomys sp. foi descrito com base em um dentário com molariformes, proveniente da localidade Talismã, no Rio Purus (Kerber et al. 2017a). Esse espécime possivelmente corresponde a uma nova unidade taxonômica, pois apresenta algumas diferenças em relação a $D$. aequatorialis Anthony, 1922 do Equador, embora os autores preferiram não nomeala até que novos dados sobre taxonomia e morfologia dos espécimes colombianos sejam publicados.

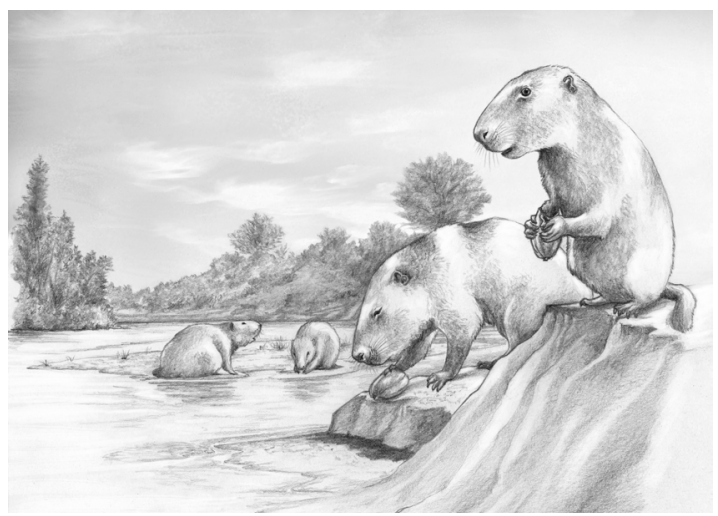

Fig. 14. Reconstituição artística de Ferigolomys pacarana. llustração por Renata Cunha 


\section{Gênero †Simplimus Ameghino, 1904}

Distribuição temporal: Neógeno

Comentários: Assim como os dinomídeos supracitados, Simplimus é outro táxon da "subfamília” Potamarchinae bastante enigmático, pois foi descrito com base em dentes isolados provenientes do Mioceno médio ("Friasense") da Argentina (Ameghino 1904, Kraglievich 1930, Vucetich 1984). Seu registro fossilífero no Brasil está restrito a poucos molariformes reportados por Sant'Anna-Filho (1994).

\section{Gênero † "Tetrastylus" Ameghino, 1886}

Distribuição temporal: Neógeno

Comentários: "Tetrastylus" é um dinomídeo de dentição eu-hipsodonte da "subfamília" Eumegamyinae. Diversas espécies foram descritas a partir de fósseis provenientes do MiocenoPlioceno da Argentina (vide Kraglievich 1926, Nasif 2009). Entretanto, esse gênero está sendo revisado, pois análises filogenéticas demonstraram que o mesmo era parafilético (Nasif 2009, Nasif et al. 2013), passando então a ser tratado como "Tetrastylus". Para o Neógeno do Brasil, Frailey (1986) reportou um molariforme de "Tetrastylus" sp. para a região amazônica.

\section{“Tetrastylus" walteri Paula Couto, 1951}

Distribuição temporal: Quaternário

Comentários: Em 1951, o paleomastozoólogo Carlos de Paula Couto descreveu uma espécie extinta de um Dinomyidae proveniente de Lagoa Santa/MG, que foi incluída em "Tetrastylus" - Tetrastylus walteri. Previamente, 8 espécies foram descritas distribuídas temporalmente do Mioceno final ao Plioceno. Como a fauna de Lagoa Santa inclui somente táxons do Quaternário, esse registro poderia corresponder ao ápice de sua distribuição temporal. Como acima relatado, as espécies de $T e-$ trastylus não formam um grupo monofilético ( $\mathrm{Na}-$ sif 2009, Nasif et al. 2013) e algumas destas devem ser realocadas em novos gêneros. Com isso, talvez a espécie descrita por Paula Couto não seria incluída em Tetrastylus sensu stricto, mas em outro gênero já conhecido ou em um novo gênero. Esse táxon atualmente encontra em revisão (obs. pes.) e futuras comparações com outros dinomídeos extintos irão contribuir para fornecer mais dados sobre esta unidade taxonômica que ajuda a documentar o declínio desse grupo tão peculiar ao longo do Quaternário sul-americano.

\section{Gênero †Telicomys Kraglievich, 1926}

Distribuição temporal: Neógeno

Comentários: Telicomys inclui dinomídeos de grande porte separados em duas espécies do Plioceno da Argentina (Kraglievich, 1926). Frailey (1986) reconheceu uma nova espécie, Telicomys amazonensis, baseado em uma porção craniana proveniente do Rio Acre, sendo esta uma espécie endêmica encontrada em depósitos do Mioceno Superior da região amazônica, e também a mais antiga (Fig. 15).

\section{Gênero †Eumegamys Kraglievich, 1926}

\section{Distribuição temporal: Neógeno}

Comentários: Eumegamys paranaensis é um dos maiores roedores que já existiram. Como grande parte dos Dinomyidae extintos, o táxon foi descrito originalmente a partir de material coletado em sedimentos do Mioceno Superior de Entre Rios (Kraglievich 1926; Nasif et al. 2013). Eumegamys sp. foi reportado para a Formação Solimões, por Sant'Anna-Filho (1994), baseado em um molariforme.

\section{† Scleromys colombianus Fields, 1957}

\section{Distribuição temporal: Neógeno}

Comentários: Originalmente descrito da fauna no Mioceno médio de La Venta, Scleromys

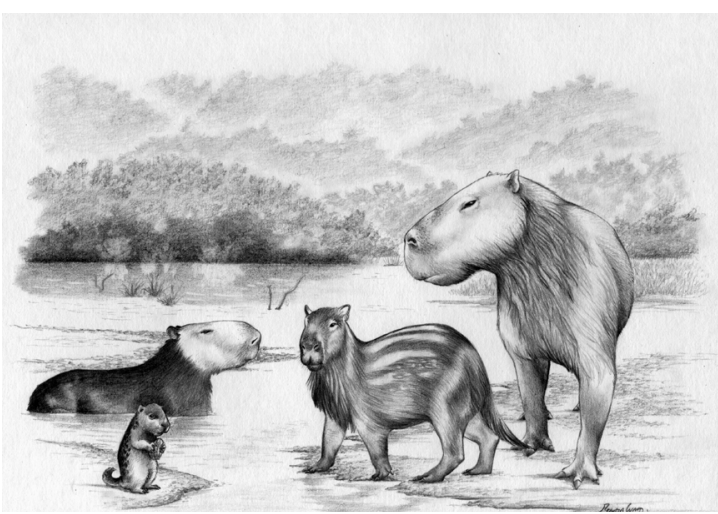

Figura 15. Reconstituição artística de roedores Dinomyidae e Neoepiblemidae do Neógeno da Formação Solimões, Bacia do Acre. Telicomys (à esquerda atrás) e Potamarchus (à direita atrás) (Dinomyidae) e Neoepiblema e Phoberomys (respectivamente) (Neoepiblemidae). Ilustração por Renata Cunha 
colombianus putativamente tem afinidade aos Dinomyidae (Fields 1957) (ver Vucetich et al. 2015b; Kerber et al. 2017a). Dentes isolados provenientes do Rio Juruá com afinidade a esse táxon foram reportados Sant'Anna-Filho (1994) e Kerber et al. (2017a) (Tabela 1).

\section{Gênero †Gyriabrus Ameghino, 1891}

Distribuição temporal: Neógeno

Comentários: Assim como Tetrastylus, Gyriabrus é um gênero de dinomídeos miocênicos que apresenta diversas espécies, mas que possivelmente está superestimado (Nasif et al. 2013). No Brasil, Paula Couto (1978a) reportou um molariforme a cf. Gyriabrus proveniente do Rio Juruá. De acordo com Kerber et al. (2017a), esse material é similar a G. holmbergi (Ameghino, 1885), espécie tipo do gênero.

\section{Niedemys piauisensis Kerber et al. 2016a}

\section{Distribuição temporal: Quaternário}

Comentários: Niedemys piauisensis é um táxon enigmático descrito com base em fósseis da região da Serra da Capivara, Piauí, e que possui afinidades aos Chinchilloidea (Kerber et al. 2016a). A série tipo está representada por molariformes isolados, eu-hipsontontes e laminares. Este registro demonstra a presença de linhagens extintas durante o Quaternário da região tropical do Brasil, não relacionadas com a fauna atual. Atualmente, o táxon encontra-se em revisão e considera-se que Niedemys piauisensis possua afinidades aos Dinomyidae (obs. pes.).

\section{Neoepiblemidae Kraglievich, 1926}

\section{Gênero $†$ Neoepiblema Ameghino, 1889}

\section{Distribuição temporal: Neógeno}

Comentários: Neoepiblema é um roedor de grande porte que inclui duas espécies - $N$. horridula (Ameghino, 1886) e Neoepiblema ambrosettianus (Ameghino, 1889) - descritas originalmente a partir de fósseis provenientes da Formação Ituzaingó, Entre Ríos, Argentina (Ameghino, 1886, 1889). Uma nova espécie de Neoepiblema (N. acreensis Bocquentin-Villanueva et al. 1990) foi proposta com base em fósseis coletados na localidade Niterói, Rio Acre, Formação Solimões (Neógeno) por Bocquentin-
Vilanueva et al. (1990), porém, posteriormente, foi sinonimizada a Neoepiblema ambrosettianus (Ameghino, 1889) por Negri \& Ferigolo (1999). Além de N. ambrosettianus, há registros de N. horridula (Ameghino, 1886) referidos por Bocquentin-Villanueva \& Negri (1993) e Sant'Anna-Filho (1997). Ressalta-se que o crânio mais completo de um neoepiblemídeo é o descrito por Negri \& Ferigolo (1999) e atribuído a Neoepiblema ambrosetianus. Recentemente, novos espécimes foram reportados (Kerber et al. 2017a,c) e corroboraram as interpretações prévias sobre a presença de duas espécies em depósitos da Formação Solimões. Atualmente, as espécies desse gênero encontram-se em revisão (obs. pes.)

\section{Gênero †Phoberomys Kraglievich, 1926}

Distribuição temporal: Neógeno

Comentários: Phoberomys habitou a América do Sul durante o final do Mioceno (Fig. 15, 16) e foi um dos maiores roedores que já existiram, atigingindo uma massa corpórea de cerca de $\sim 700$ kilogramas (Sanchez-Villagra et al. 2003). Fósseis atribuídos a esse gênero têm sido reportados para o Neógeno da Amazônia. Patterson (1942) descreveu uma espécie nova baseada dentes inferiores e assignou a uma espécie: P. bordasi. Paula Couto (1978a) identificou um fêmur como pertencente a $P$. burmeisteri (Ameghino, 1886) e Sant'AnnaFilho (1997) identificou molariformes a $P$. minima (Kraglievich, 1940). Kerber et al. (2017a) questionaram a validade taxonômica de $P$. bordasi, e sugeriram que até que espécimes mais completos sejam encontrados, os fósseis atribuídos ao gênero Phoberomys provenientes do

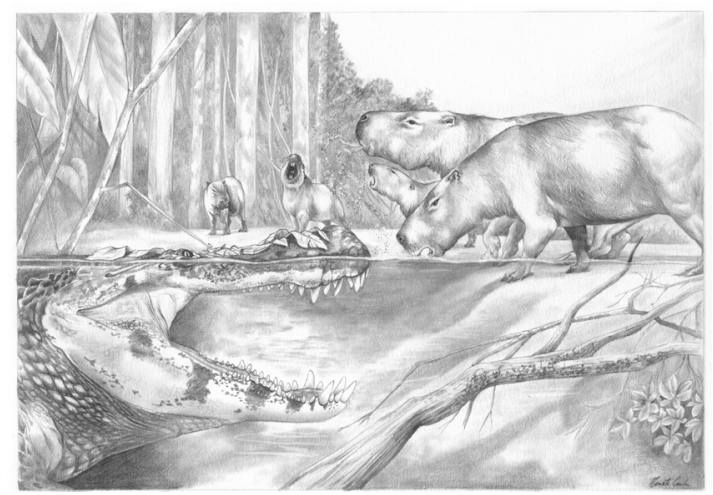

Fig. 16. Neoepiblemídeos da Formação Solimões, Bacia do Acre e paleambiente. Ilustração por Renata Cunha 
Acre devam ser considerados como Phoberomys sp. Atualmente duas espécies desse gênero são consideradas válidas $-P$. burmeisteri Kraglievich, 1926 e P. pattersoni (Mones, 1980) (Carrillo \& Sánchez-Villagra 2015; Rasia \& Candela 2017).

\section{Considerações finais}

A paleontologist does not have the luxury of designing experiments to test hypotheses; the experiments, termed evolution, have already occurred. It is the job of the paleontologist to use the sprse evidence of fossil remains, along with the surviving results of evolution, in order to discover the experiments. Any respect of morphology, from molecules to entire animals, can yield valuable evidence."

(Jonh H. Wahlert $)^{5}$

Os fósseis de caviomorfos do Brasil tem registrado, até o momento, pelo menos três períodos da história evolutiva do grupo: Oligoceno final - caracterizado por formas de pequeno porte; Neógeno - com formas de médio a grande porte, bastante distintas das atuais (e.g. Neoepiblemidae e Dinomyidae) e uma relação biogeográfica com localidades da Argentina ("Mesopotamiense") e da Venezuela (Urumaco); e Quaternário. Durante o Pleistoceno final e início do Holoceno as maiores diferenças em relação à fauna moderna não estão na diversidade e sim nos padrões paleobiogeográficos promovidos pelas alterações climáticas ao longo desse período (Kerber 2014) (Fig. 17). Entretanto, a região tropical apresenta grande quantidade de táxons extintos e endêmicos, porém relacionados às formas modernas. $\mathrm{Na}$ região sul do Brasil, durante o Pleistoceno final e início do Holoceno, verifica-se que o endemismo é baixo; no entanto observa-se mudança faunística, provavelmente associada a alterações climáticas e ambientais que ocorreram nesse período (Fig. 17). De forma geral, é no Pleistoceno final e início do Holoceno que a fauna moderna começa a se estabelecer.

Quanto à cronologia das faunas, há problemas na resolução temporal. No caso dos roedores do Neógeno, os fósseis do Rio Juruá, Formação Solimões, foram estudados por Paula Couto (1978a, 1983), Sant'Anna-Filho (1994) e Kerber et al. (2017a). Esta fauna, segundo Sant'Anna-Filho (1994), exibe um conjunto de táxons do Mioceno médio e final. No caso dos roedores do Quaternário, o maior problema talvez seja a falta de datações

\footnotetext{
5 Wahlert, J.H. 1985. Cranial Foramina of Rodents. In: Luckett, W.P.; Hartenberger, J.L. Evolutionary relationships among rodents: a multidisciplinary analysis. New York, Plenum Press, 1985, 311-354.
}

absolutas associadas, principalmente em cavernas, problemática já observada por Paula Couto (1950).

Como futuras perspectivas no estudo dos roedores fósseis do Brasil, espera-se que coleta com controle estratigráfico de novos espécimes, revisão de fósseis depositados em coleções científicas e refinamento sobre o conhecimento anatômico das unidades taxonômicas, contribuirão para uma melhor compreensão sobre a diversidade e evolução desse grupo.

\section{Agradecimentos}

Este artigo foi parcialmente desenvolvido durante o projeto de doutorado do presente autor. Agradeço a Ana Maria Ribeiro, que orientou a tese; Jorge Ferigolo, Martín Ubilla e Norma Nasif pela leitura da primeira versão do manuscrito; CNPq por financiamento (CNPq 141986/2011-5;

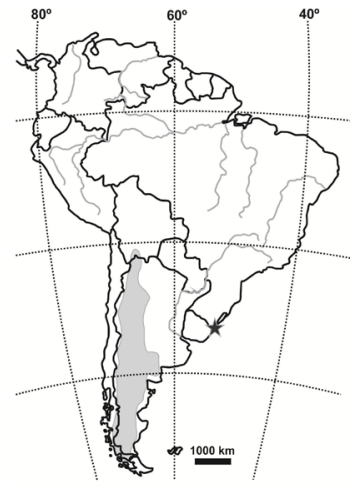

Microcavia spp.

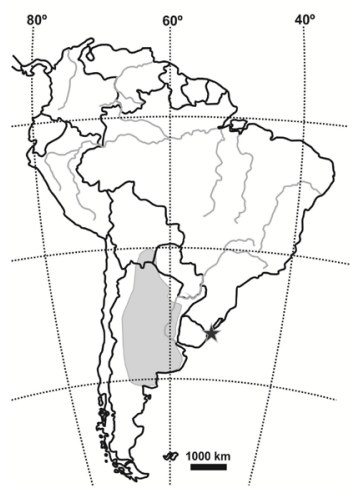

Lagostomus maximus

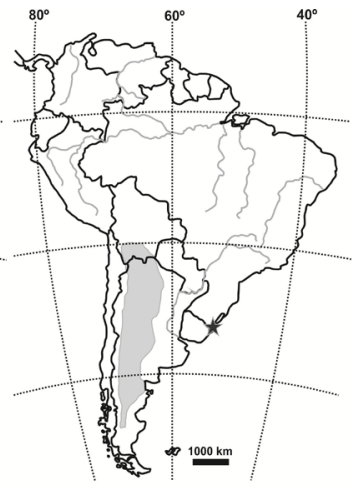

Dolichotis spp.

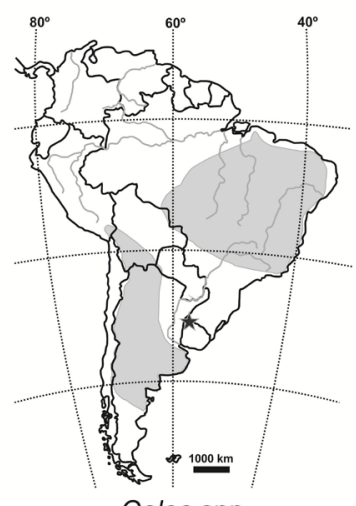

Galea spp.
Fig. 17. Localidades pleistocênicas (estrelas) no sul do Brasil com regristro fossilífero de táxons que atualmente não habitam a região (Microcavia spp., Dolichotis spp., Lagostomus maximus and Galea spp.) e sua distribuição atual (baseado em Jackson et al. 1996, Einsenber \& RedFord 1999, Ubilla et al. 2008 e Bezerra 2008). Esses registros evidenciam diferenças na distribuição geográfica durante o Pleistoceno final, em relação a distribuição atual 
163168/2014-8; 201356/2015-5); revisores e editores pelos comentários que melhoraram a qualidade do texto.

\section{Referências}

Adkins R.M., Gelke E.L., Rowe D., Honeycutt R.L. 2001. Molecular phylogeny and divergence time estimates for major rodent groups: evidence from multiple genes. Mol. Biol. Evol., 18:777-791.

Antoine P. -O., Marivaux L., Croft D.A., Billet G., Ganerød M., Jaramillo C., Martin T., Orliac M.J., Tejeda J., Altamirano A.J., Duranthon F., Fanjat G., Rouse S., Gismondi, R.S. 2012. Middle Eocene rodents from Peruvian Amazonia reveal the pattern and timing of caviomorph origin and biogeography. Proc. R. Soc. Lond. B. Biol Sci., 279:1319-1326

Anthony H.E. 1922 A new fossil rodent from Ecuador. Am. Mus. Novit., 35:1-4.

Ameghino, F. 1886. Contribuciones al conocimiento de los mamíferos fósiles de los terrenos terciarios antiquos del Paraná. Boletín de la Academia de Ciencias de Córdoba, 9:1-228.

Ameghino, F. 1889. Contribución al conocimiento de los mamíferos fósiles de la República Argentina. Actas Acad. Nac. Ciencias Córdoba, Córdoba, 6:1-1027.

Ameghino F. 1904. Nuevas especies de mamíferos Cretáceos y Terciarios de la República Argentina. Anales de la Sociedad Científica Argentina, 57: 162-175, $327-$ 341, 58:35-41, 56-71, 182-192, 225-290.

Ameghino F. 1907. Notas sobre una pequeña colección de huesos de mamíferos procedentes de las grutas calcáreas de Iporanga, en el estado de São Paulo Brazil. Rev. Mus. Paul., 3(7):69-124.

Ameghino F. 1898. Sinopsis geológico-paleontologica. Segundo Censo de La República Argentina, 1:111-225.

Asher R., Bennet N., Lehmann T. The new framework for understanding placental mammal evolution. BioEssays, 31:853-864.

Archibald J.D., Averianov A.O., Ekdale E.G. 2001. Late Cretaceous relatives of rabbits, rodents, and other extant eutherian mammals. Nature, 414:62-65.

Arnal M., Vucetich M.G. 2015. Main radiation events in Pan-Octodontoidea (Rodentia, Caviomorpha). Zool. J. Linnean. Soc., 175(3):587-606.

Auler A.S., Piló L.B., Smart P.L., Wang X., Hoffmann D., Richards D.A., Edwards R.L., Neves W.A., Cheng H. 2006. U-series dating and taphonomy of Quaternary vertebrates from Brazilian caves. Palaeogeogr. Palaeoclimatol. Palaeoecol., 240:508-522.

Bergqvist L.P., Ribeiro, A.M., Bocquentin-Villanueva, J. Primata, Roedores e Litopternas do Mio-Plioceno da Amazônia Sul-Ocidental (Formação Solimões, Bacia do Acre), Brasil. 1998. Geología Colombiana, 23:19-29.

Bertrand O.C., Flynn J.J., Croft, D.A., Wyss, A.R. 2012.
Two new taxa (Caviomorpha, Rodentia) from the Early Oligocene Tinguiririca Fauna (Chile). Am. Mus. Novit., 3750:1-36.

Bezerra A.M.R. 2008. Revisão taxonômica do gênero Galea Meyen, (1832) (Rodentia, Caviidae, Caviinae). Brasilia: Pós-Grad. Bio. Ani. UNB. 125p. (Tese de Doutorado).

Bezerra A.M.R., Oliveira, J.A. 2010. Taxonomic implications of cranial morphometric variation in the genus Clyomys Thomas, 1916 (Rodentia: Echimyidae).J. Mammal., 91(1):260-272.

Bocquentin-Villanueva J., Negri, F.R. 1993. Ocorrência do roedor Neoepiblema horridula (Chinchilloidea, Neoepiblemidae) no Mioceno superior-Plioceno da Localidade Talismã, Estado do Amazonas, Brasil. Ameghiniana, 30(1): R.

Bocquentin-Villanueva J. B., Souza Filho, J.P., Negri, F.R. 1990. Neoepiblema acreensis, sp. n. (Mammalia, Rodentia) do Neógeno do Acre, Brasil. Bol Mus Para Emílio Goeldi, 2:65-72.

Burmeister G.H. 1885. Examen crítico de los mamíferos y reptiles fósiles denominados por D. Augusto Bravard y mencionados en su obra precedente. Anales Mus. Nac. Hist. Nat. Buenos Aires, 3:93-174.

Brandt J.F. 1855. Beiträge zur nähern Kenntniss der Säugethiere Russlands. Mémoire de l'Académie impériale des Sciences, St. Petersburg, Physique, Mathématique, et Naturalistique, 6(9):1-365.

Candela A., Nasif N.L. 2006. Systematics and biogeographic significance of Drytomomys typicus (Scalabrini in Ameghino, 1889) nov. comb., a Miocene Dinomyidae (Rodentia, Hystricognathi) from Northeast of Argentina. Jahrb. Geol. Palaontol/Monatschefte, 3:165-181.

Candela A.M., Rasia L.L. 2012. Tooth morphology of Echimyidae (Rodentia, Caviomorpha): homology assessments, fossils, and evolution. Zool.J. Linnean. Soc., 164:451-480.

Campbell K.E., Frailey C.D, Romero-Pittman L. 2006. The Pan-Amazonian Ucayali Peneplain, late Neogene sedimentation in Amazonia, and the birth of the modern Amazon River system. Palaeogeogr. Palaeoclimatol. Palaeoecol., 239:166-219.

Campos C.M., Tognelli M.F. Ojeda R.A. 2001. Dolichotis patagonum. Mamm. Species, 652:1-5.

Carranza-Castañeda O. 2016. Roedores caviomorfos (Rodentia Hydrochoeridae) del Blancano temprano-tardío - Irvingtoniano de los estados de Guanajuato, Jalisco y Sonora, México: relación con Phugatherium dichroplax. Rev. Mex. Cienc. Geol., 33(3): 297-315.

Carranza-Castañeda O., Miller W.E. 1988. Roedores caviomorfos de la Mesa Central de México, Blancano Temprano (Plioceno Tardío) de la fauna local Rancho Viejo, Estado de Guanajuato. UNAM, Inst. Geo. Revista, 7:182-199.

Carrillo J.D., Sánchez-Villagra M. 2015. Giant rodents 
from the Neotropics: diversity and dental variation of late Miocene neoepiblemid remains from Urumaco, Venezuela. Paläontol Z. 89:1057-1071.

Cartelle C. 1994. Tempo Passado. Mamíferos do Pleistoceno em Minas Gerais. Belo Horizonte: Editorial Palco. $131 \mathrm{p}$.

Cartelle C. 1999. Pleistocene mammals of the Cerrado and Caatinga of Brazil. In: Eisenberg J.F., Redford K.H. eds. 1999. Mammals of the Neotropics. Chicago: The Univ. Chicago Press. p. 27-46.

Castilho P.V., Simões-Lopes, P.C. 2001. Zooarqueologia dos mamíferos aquáticos e semi-aquáticos da Ilha de Santa Catarina, sul do Brasil. Zoologia, 18(3):719-727.

Castro M.C., Langer M.C. 2011.The mammalian fauna of Abismo Iguatemi, southeastern Brazil. J. Caves Karst. Stud., 73(2):83-92.

Catzeflis F., Patton J. 2008. Echimys chrysurus. In: IUCN 2013. In: IUCN Red List of Threatened Species. Version 2013.2. URL < www.iucnredlist.org>. Acesso 29/03/2014

Catzeflis F., Patton J., Percequillo A., Bonvicino C., Weksler M. 2008a. Euryzygomatomys spinosus. In: IUCN 2013. IUCN Red List of Threatened Species. Version 2013.2. URL www.iucnredlist.org. Acesso 13/01/2014

Catzeflis F., Patton J., Percequillo A., Bonvicino C., Weksler M. 2008b. Kannabateomys amblyonyx. In: IUCN 2013. IUCN Red List of Threatened Species. Version 2013.2. URL<www.iucnredlist.org>. Acesso 13.01.2014.

Chahud, A. 2005. Paleomastozoologia do Abismo Ponta de Flecha, Iporanga, SP. In: Congr. Latino-Amer. Paleont. Vertebrados, 2, 2005. B. resumos. Rio de Janeiro, Museu Nacional/UFRJ. p. 76-77.

Cozzuol M. 2006. The Acre vertebrate fauna: diversity, geography and time. J. South Am. Earth Sci., 21:185-203.

Cozzuol M.A., Holanda E.C., Nascimento, E.R.Do. Weiss F.L. 2006. Registro do gênero Neochoerus (Rodentia, Caviomorpha, Hydrochoeridae) para o Pleistoceno da Amazônia Sul-Ocidental. Paleontologia em Destaque (Boletim Informativo da Sociedade Brasileira de Paleontologia), 53: 43-44.

Cox P.G., Hautier L. eds. 2015. Evolution of the rodents: Advances in Phylogeny, Functional morphology and Development. Cambridge: Cambridge Univ. Press. 608p.

Dantas M.A.T. 2009. Primeiro registro de fósseis de mamíferos pleistocênicos em caverna de Sergipe, Brasil. Rev. Bras. Paleontolog., 12(2):161-164.

Debry R.W., Sagel R.M. 2001. Phylogeny of Rodentia (Mammalia) inferred from the nuclear-encoded gene IRBP. Mol. Phylogenet. Evol., 19:290-301.

Deschamps C.M., Olivares A.I., Vieytes E.M., Vucetich M.G. 2007. Ontogeny and diversity of the oldest capybaras (Rodentia, Hydrochoeridae, Late Miocene of Argentia). J. Vert. Paleontol., 27(3):683-692.
Deschamps C.M., Vucetich M.G., Montalvo C.I., Zárate M.A. 2013. Capybaras (Rodentia, Hydrochoeridae, Hydrochoerinae) and their bearing in the calibration of the late Miocene-Pliocene sequences of South America. J. South Am. Earth Sci., 48:145-158.

Dunnum J., Salazar-Bravo J., 2010. Phylogeny, evolution and systematics of the Galea musteloides complex (Rodentia, Caviidae). J. Mammal., 91:243-259.

Eisenberg J.F., Redford K.H. eds. 1999. Mammals of the Neotropics - The Central Neotropics: Ecuador, Peru, Bolivia, Brazil (Vol. 3). Chicago: Univ. of Chicago Press. 609 p.

Emmons L.H., Feer F.1997. Neotropical rainforest mammals: a Field Guide. $2^{\text {a }}$ ed. Chicago: Univ. Chicago Press. 2167p.

Emmons L.H., Leite Y.L.R., Kock, D., Costa, L.P. 2002. A review of the named forms of Phyllomys (Rodentia: Echimyidae) with the description of a new species from coastal Brazil. Am. Mus. Novit., 3380:1-40.

Emmons L.H., Vucetich M.G. 1998. The identity of Winge's Lasiuromys villosus and the description of a new genus of Echimyid Rodent (Rodentia: Echimyidae). Am. Mus. Novit., 3223:1-12.

Esselstyn J.A., Achmadi A.S., Rowe K.C. 2012. Evolutionary novelty in a rat with no molars. Biol. Lett., 8:990-993.

Fabre P.-H., Hautier L., Douzery E.J.P. 2015. A synopsis of rodent molecular phylogenetics, systematics and biogeography. In: Cox P.G. Hautier L. eds. 2015. Evolution of the rodents: Advances in Phylogeny, Functional morphology and Development. Cambridge: Cambridge Univ. Press. p. 19-69.

Ferreira D., Silva A.K., Matos C.H.C., Hadler, P., Hsiou, A. 2012. Assembleia holocênica de vertebrados de pequeno porte do Sítio Alcobaça, Estado de Pernambuco, Brasil. Rev. Bras. Paleontolog., 15(3):359-370.

Ferreira T.M.P., Olivares, I.A., Kerber, L., Dutra R.P., Ávilla L.S. 2016. Late Pleistocene echimyid rodents (Rodentia, Hystricognathi) from northern Brazil. An. Acad. Bras. Cienc., 88(2):829-845.

Fields R.W. 1957. Hystricomorph rodents from the late Miocene of Colombia, South America. Contrib. Sci. Mus. Nat. His. Los Angeles, 32:273-404.

Flynn J.J., Wyss A.R., Croft D.A., Charrier R. 2003. The Tinguiririca Fauna, Chile: biochronology, paleoecology, biogeography, and a new earliest Oligocene South American Land Mammal 'Age'. Palaeogeogr. Palaeoclimatol. Palaeoecol., 195:229-259.

Frailey C.D. 1986. Late Miocene and Holocene mammals, exclusive of the Notoungulata, of the Rio Acre region, western Amazonia. Contrib. Sci. Mus. Nat. His. Los Angeles, 374:1-46.

Frailey C.D., Campbell Jr, K.E. 2004. Paleogene rodents from Amazonian Peru: The Santa Rosa local fauna. Natural History Museum of Los Angeles County, Science Series, 40:71-130.

Francia A., Carlini A.A., Zurita A. E., Verzi D.H. 2012. 
Galea (Rodentia, Caviidae) in the late Pleistocene of Corrientes Province (Argentina): taxonomic and paleobiogeographic implications. Jahrb. Geol. Palaontol/Abhandlungen, 266(2):173-184.

Guerin C., Curvello M.A., Faure M., Hugueney M., Mourer-Chauvire C. 1993. La faune pléistocène du Piauí (Nordeste du Brésil): implications paléoécologiques et biochronologiques. Quaternaria Nova, 3:303-341.

Hadler P., Cherem J.J., Turbay R., Alverti A., Pardiñas U.F.J. 2016. Diversidade de pequenos mamíferos (Didelphimorphia e Rodentia) do Holoceno do nordeste do estado do Rio Grande do Sul, Brasil: implicações taxonômicas e paleoambientais. Rev. Bras. Paleontolog., 19(1):127-144.

Hadler P., Verzi D.H., Vucetich M.G., Ferigolo J., Ribeiro A.M. 2008. Caviomorphs (Mammalia, Rodentia) from the Holocene of Rio Grande do Sul State, Brazil: systematics and paleonviromental context. Rev. Bras. Paleontolog., 11(2):97-116.

Hafner C.H., Hafner M.S. 1988. Heterochrony in Rodents. In: Mcknney, M.L. (ed). Heterochrony in evolution: a multidisciplinary approach. New York: Plenum Press, p. 217-235.

Hartenberger J.L. 1985. The order Rodentia: Major questions on their evolutionary origin, relatioships and suprafamilial systematics. In: Luckett, W.P., Hartenberger, J.L. 1985. Evolutionary relationships among rodents: a multidisciplinary analysis. New York: Plenum Press. p. 1-33.

Hartenberger, J.L. 1998. Description de la radiation des Rodentia (Mammalia) du Palèocéne supériuer au Miocéne; incidences phylogénétiques. C.R. Acad. Sci., Ser. IIa: Sci. Terre Planets, 326:439-444.

Hautier L., Cox P.G., Lebrum R. 2015. Grades and clades among rodents: the promise of geometric morphometrics In: Cox, P.G., Hautier L. eds. Evolution of the rodents: Advances in Phylogeny, Functional morphology and Development. Cambridge: Univ. Press. p. 277-279.

Hay O. P. 1926. A collection of Pleistocene vertebrates from southwestern Texas. Proceedings of the U.S. National Museum, 68(24):1-18.

Hsiou A.S., Bissaro Júnior M.C., Kerber L., Ghilardi R.P., Negri F.R., Sousa-Filho J.P., Guilherme E., Maciente A., Ribeiro A.M. 2017. Novas informacões sobre a idade da Formação Solimões (Bacia do Acre), Neógeno da Amazônia Brasileira. In: Congresso Brasileiro de Paleontologia, 25, 2017. Boletim de Resumos - Ribeirão Preto. p. 142.

Hoffstetter R. 1972. Origini et dispersión des rongeurs hystricognathes. C.R. Acad. Sci., 274:2867-2870.

Hoffstetter, R. 1975. El origen de los Caviomorpha y el problema de los Hystricognathi (Rodentia). Actas Del Primer Congreso Argentino De Paleontologia Y Bioestratigrafia, 1, 1974. Actas, Tucumán, Univ. Nac. de Tucumán. p. 505-528.
Hoffstetter R., R. Lavocat. 1970. Découverte dans le Déséadien de Bolivie de genres pentalophodontes appuyant les affinités africaines des rongeurs Caviomorphes. C.R. Acad. Sci., 271:172-175.

Honeycutt, R. 2009. Rodents (Rodentia). In: Hedges S.B., Kumar S. eds. 2009. The tree of life. Oxford: Oxford Univ. Press. p. 490-494.

Honeycutt R., Frabotta L.J., Rowe D.L. 2007. Rodent Evolution, Phylogenetics, and Biogeography, In: Wolff, J.O. Sherman P.W. 2007. Rodent societies: an ecological and evolutionary perspective. Chicago and London: Univ. of Chicago Press. p. 8-23.

Horovitz I., Sanchez-Villagra M.R., Martin T., Aguilera O. A. 2006. The fossil record of Phoberomys pattersoni Mones 1980 (Mammalia, Rodentia) from Urumaco (Late Miocene, Venezuela), with an analysis of its phylogenetic relationships. J. Syst. Palaeontol, 4(3):293-306.

Hubbe A., Haddad-Martim P.M., Hubbe M., Mayer E. L., Strauss A., Auler A. S., Piló L. B., Neves W. A. 2011. Identification and importance of critical depositional gaps in pitfall cave environments: The fossiliferous deposit of Cuvieri Cave, eastern Brazil. Palaeogeogr. Palaeoclimatol. Palaeoecol., 312:77-78.

Huchon D., Catzeflis F.M., Douzery E.J.P. 2000. Variance of molecular datings, evolution of rodents, and the phylogenetic affinities between Ctenodactylidae and Hystricognathi. Proc. R. Soc. Lond. B. Biol Sci., 267:393-402.

Huchon D., Douzery E.J.P. 2001. From the Old World to the New World: A Molecular Chronicle of the Phylogeny and Biogeography of Hystricognath Rodents. Mol. Phylogenet. Evol., 20(2):238-251.

Huchon D., Madsen O., Sibbald M.J.J.B., Ament K., Stanhope M.J., Catzeflis F., De Jong W.W., Douzery E.J.P. 2002. Rodent phylogeny and a timescale for the evolution of Glires: evidence from an extensive taxon sampling using three nuclear genes. Mol. Biol. Evol., 19:1053-1065.

Iack-Ximenes G.E. 1999. Sistemática da família Dasyproctidae Bonaparte, 1838 (Rodentia, Hystricognathi) no Brasil. São Paulo: Pós-Grad. Zool. USP. 429p. (Dissert. Mestrado).

Jackson J.E., Branch L.C., Vilarreal D. 1996. Lagostomus maximus. Mamm. Species, 543:1-6.

Kerber L. 2014. Contribuições ao estudo dos roedores (Mammalia: Rodentia) fósseis do brasil: aspectos taxonômicos, morfológicos e paleoambientais. Porto Alegre: Pós-Grad. Geosc. UFRGS. 378p. (Tese de Doutorado).

Kerber L., Bissaro Júnior M.C., Negri, F.R., Souza-Filho J.P., Guilherme E., Hsiou A.S. 2017b. A new rodent (Caviomorpha: Dinomyidae) from the upper Miocene of southwestern Brazilian Amazonia. Hist. Biol. No prelo.

Kerber L., Hadler P., Ribeiro A.M. 2012a. Late Quaternary caviomorph rodents from southern Brazil: 
systematics, palebiogeography, faunal turnover and landscape evolution. In: Simp. Bras. Paleont. Vertebrados, 8, 2012. Paleontologia em Destaque - Edição Especial 2012 - Recife. p. 132.

Kerber L., Lopes R.P., Vucetich M.G., Ribeiro A.M., Pereira, J.C. 2011b.Chinchillidae and Dolichotinae rodents (Rodentia, Hystricognathi, Caviomorpha) from the late Pleistocene of southern Brazil. Rev. Bras. Paleontolog., 14(3):229-238.

Kerber L., Mayer E.L., Ribeiro A.M., Vucetich M.G. 2016a. Late Quaternary caviomorph rodents (Rodentia: Hystricognathi) from the Serra da Capivara, northeastern Brazil, with description of a new taxon. Hist. Biol., 28:439-259.

Kerber L., Negri F.R., Ribeiro A.M., Vucetich M.G., Souza-Filho J.P. 2016b. Late Miocene potamarchine rodents (Caviomorpha: Dinomyidae) from southwestern Amazonia, Brazil (northern South America): with description of new taxa. Acta Palaeontol. Pol., 61:191-203.

Kerber L., Negri F.R., Ferigolo J., Mayer E.L., Ribeiro A.M. 2017: Modifications on fossils of neoepiblemids and other South American rodents. Lethaia, 50:149-161.

Kerber L., Negri F.R., Ribeiro A.M., Nasif N., Ferigolo J., Souza-Filho J. 2017a. Tropical fossil caviomorph rodents from the Southwestern Brazilian Amazonia in the context of the South American faunas: Systematics, Biochronology, and Paleobiogeography.J. Mammal. Evol. 24:57-70.

Kerber L., Ribeiro A.M. 2011. Capybaras (Rodentia, Hystricognathi, Hydrochoeridae) from the late Pleistocene of southern Brazil.Jahrb. Geol. Palaontol/ Abhandlungen, 261(1):1-18.

Kerber L., Ribeiro A.M., Lessa G., Cartelle C. 2014. Late Quaternary fossil record of Myocastor Kerr, 1792 (Rodentia: Hystricognathi: Caviomorpha) from Brazil with taxonomical and environmental remarks. Quat. Int., 352:147-158.

Kerber L., Ribeiro A.M., Oliveira E.V. 2011a. The first record of Galea Meyen, 1832 (Rodentia, Hystricognathi, Caviidae) in the late Pleistocene of southern Brazil and its paleobiogeographic implications. Alcheringa, 35:445-457.

Kerber L., Silva D., Sedor F., Ribeiro A.M. 2012b. Ocorrência de Cuniculus Brisson, 1762 (Rodentia: Caviomorpha) no Quaternário do sul do Brasil (Estado do Paraná) e comparação dos forames cranianos com Dasyproctidae e outros Cavioidea. In: Reunião Da Sociedade Brasileira De Paleontologia - Paleo RS, 2012. Livro de Resumos, São João do Polêsini, p. 21.

Kraglievich L. 1926. Los grandes roedores terciarios de la Argentina y sus relaciones com ciertos géneros Pleistocenos de las Antillas. Anais del Museo Nacional de Historia Natural de Buenos Aires, 34:122-135.

Kraglievich L. 1930. Descripción de un interesante roedor eumegámido descubierto en el Uruguay: Gyria- brus teisseirei n. sp. Revista de la Sociedad de Amigos de la Arqueología, 14:219-224.

Kraglievich L. 1941. Monografía del gran carpincho corredor plioceno Protohydrochoerus (Rovereto) y formas afines. In: Torcelli A.J., Morelli C.A. eds. 1941, Obras de Geología y Paleontología 3 (Obras completas y trabajos científicos inéditos). Buenos Aires: Ministerio de Obras Públicas de la Provincia de Buenos Aires. p. 487-556.

Landry Jr, S.O. 1999. A Proposal for a new classification and nomenclature for the glires (Lagomorpha and Rodentia). Mitt. Mus. Nat.kd. Berl., Zool. Reihe, 75(2):283-316.

Latrubesse E.M., Cozzuol M., Silva-Caminha S.A.F., Rigsby C.A., Absy M.L., Jaramillo C. 2010. The Late Miocene paleogeography of the Amazon Basin and the evolution of the Amazon River system. Earth-Sci. Rev., 99:99-124.

Latrubesse E.M., Silva S.A.F., Cozzuol M., Absy M.L. 2007. Late Miocene continental sedimentation in southwestern Amazonia and its regional significance: Biotic and geological evidence. J. South Am. Earth Sci., 23:61-80.

Lavocat R. 1969. La systematique des rongeurs hystricomorphes et la dérive des continents. C.R. Acad. Sci., 269:1496-1497.

Lavocat R. 1971. Systematic affinities of the caviomorphs and phiomorphs and the African origin of the caviomorphs. An. Acad. Bras. Cienc., Suplemento, 43:515-522.

Leite R.N., Kolokotronis S-.O., Almeida F.C., Werneck F.P., Rogers D.S, Wesler, M. 2014. In the Wake of Invasion: Tracing the Historical Biogeography of the South American Cricetid Radiation (Rodentia, Sigmodontinae). PLoS ONE 9(6) e100687: 1-12.

Leite Y.L.R. 2003. Evolution and systematics of the Atlantic tree rats, genus Phyllomys (Rodentia, Echimyidae), with description of two new species. Univ. Calif. publ. zool., 132:1-118.

Lessa G., Cartelle C., Manduca E.G. 2008. Reevaluation of rodent assemblages from Pleistocene/Holocene of Bahia, Brazil: morphologic and environmental considerations. In: Congresso Latino Americano de Paleontología de Vertebrados, 3, 2008. Libro de Resúmenes, Neuquén. p. 137.

Locks M., Montenegro E. 1985. Contribuição à paleontologia do "Grande abrigo da Lapa Vermelha Emperaire”, Pedro Leopoldo, MG, Brasil. No 1 - um novo cavíineo quaternário (Mammalia-Rodentia). In: Campos D.A., Ferreira C.S., Brito I.M., Viana C.F. org. 1985. Coletânea de Trabalhos Paleontológicos, DNPM, p. 81-86.

Lund P.W. 1837. Om huler I kalksteen I det Indre af Brasilien, der tildeels indeholde fossile knokler. Det Kongelige Danske Videnskabernes Selskabs naturvidenskabelige og Mathematiske Afhandlinger, 7:307-337. Lund P.W. 1839. Blik paa Brasiliens Dyreverden för 
Sidste Jordomvaeltning. Anden Afhandling: Pattedyrene. Det Kongelige Danske Videnskabernes Selskabs naturvidenskabelige og Mathematiske Afhandlinger, 8:61-144.

Lund P.W. 1841. Tillaeg til de to Sidste Afhandlinger over Brasiliens Dyreverden för Sidste Jordomvaeltning. Det Kongelige Danske Videnskabernes Selskabs naturvidenskabelige og Mathematiske Afhandlinger, 8:273-296.

Macphee R.D.E. 2011. Basicranial morphology and relationships of Antillean Heptaxodontidae (Rodentia, Ctenohystrica, Caviomorpha). Bull. Am. Mus. Nat. Hist., 363:1-70.

Marivaux L., Vianey-Liaud M., Jaeger J.-J. 2004. High-level phylogeny of early Tertiary rodents: dental evidence. Zool. J. Linnean Soc., 142:105-134.

Marshall L.G., Webb S.D., Sepkoski J.J., Jr., Raup D.M. 1982. Mammalian evolution and the Great American Interchange: Science, 215:1351-1357.

Martin T. 1994. African origin of caviomorph rodents is indicated by incisor enamel microstructure. $\mathrm{Pa}$ leobiology, 20:5-13.

Martin T. 2005. Incisor Schmelzmuster Diversity in South America's Oldest Rodent Fauna and Early Caviomorph History.J. Mammal. Evol., 12(3/4):405417.

Mayer E.L., Hubbe A., Kerber L., Haddad-Martim P., Neves W. Taxonomic, biogeographic, and taphonomic reassessment of a large extinct species of paca from the Pleistocene of Brazil. Acta Palaeontol. Pol., 61(4):743-758.

Mckenna M.C., Bell S.K. 1997. Classification of mammals above the species level. New York, Columbia Univ. Press, 1997, p. 631.

Meng J., Wyss A.R. 2001.The Morphology of Tribosphenomys (Rodentiaformes, Mammalia): Phylogenetic Implications for Basal Glires. J. Mammal. Evol., 8(1):1-71.

Meng J., Wyss A.R. 2005. Glires (Lagomorpha, Rodentia). In: Rose K.D., Archibald J.D. eds. 2005. The rise of placental mammals: origins and relationships of the major extant clades. Baltimore: The Johns Hopkins Univ. Press. p. 145-158.

Meng J., Hu Y.-M., Li C.-K. 2003. The osteology of Rhombomylys (Mammalia, Glires): implications for the phylogeny and evolution of Glires. Bull. Am. Mus. Nat. Hist., 275:1-247.

Mones A. 1991. Monografía de la Familia Hydrochoeridae (Mammalia,Rodentia). Sistemática-Paleontología-Bibliografía. Cour. Forsch.-Inst. Senckenberg, 134:1-235.

Mones A., Ojasti J. 1986. Hydrochoerus hydrochaeris. Mamm. Species, 264:1-7.

Mones A., Toledo P.M. 1989. Primer hallazgo de Euphilus Ameghino, 1889 (Mammalia: Rodentia: Neoepiblemidae) en el Neogeno del estado de Acre, Brasil. Comunicaciones paleontológicas del Museu de Historia Natural de Montevideo, 21(2):1-15.
Montgelard C., Bentz S., Tirard C., Verneau O., Catzeflis F.M. 2002. Molecular systematics of Sciurognathi (Rodentia): The mitochondrial Cytochrome $\mathrm{b}$ and 12S rRNA genes support the Anomaluroidea (Pedetidae and Anomaluridae). Mol. Phylogenet. Evol., 22:220-233.

Moojen, J. 1952. Os Roedores do Brasil. Rio de Janeiro: Ministerio da Educação e Saúde, Inst. Nacional do Livro. 214 p.

Moojen J., Locks M., Langguth A. 1997. A new species of Kerodon Cuvier, 1825 from the state of Goiás, Brazil (Mammalia, Rodentia, Caviidae). Bol. Museu Nac., 377:1-10.

Moura R.T., Da Fonseca G.A.B. 2008. Callistomys pictus. In: IUCN 2013. IUCN Red List of Threatened Species. Version 2013.2. www.iucnredlist.org. Acesso 13/01/2014

Murphy W.J., Eizirik E., O’Brien S.J., Madsen O., Scally M., Douady C.J., Teeling E., Ryder O.A., Stanhope M.J., de Jong W.W., Springer M.S. 2001. Resolution of the early placental mammal radiation using Bayesian phylogenetics. Science, 294:2348-2351.

Murphy W.J., Johnson W.E., Zhang Y.P., Ryderk O.A., O'Brienn S.J. 2001. Molecular phylogenetics and the origins of placental mammals. Nature, 409:614618.

Nasif N. 2009. Los Dinomyidae (Rodentia, Caviomorpha) del Mioceno superior del noroeste argentino. Su anatomía cráneo-dentaria. Tucumán: FNS/UNT/UNT. 362p. (Tesis Doctoral).

Nasif N., Candela A.M., Rasia L., Madozzo Jaén M.C., Bonini R. 2013. Atualización del conocimento de los roedores de la Mesopotamia Argentina: aspectos sistemáticos, evolutivos y paleobiogeográficos. Asociación Paleontológica Argentina -- Pub. Esp., 14:153-169.

Nasif N., Esteban G.I., Ortiz P.E. 2009. Novedoso hallazgo de egagrópilas en el Mioceno tardío, Formación Andalhuala, provincia de Catamarca, Argentina. Serie Temas de Paleontología I - Correlación Geológica, 25:105-114.

Nedbal M.A., Honeycutt R.L., Schlitter D.A. 1996. Higher level systematics of rodents (Mammalia, Rodentia): evidence from the mitochondrial $12 \mathrm{~S}$ rRNA gene. J. Mammal. Evol., 3:201-237,

Negri F.R., Ferigolo, J. 1999. Anatomia craniana de Neoepiblema ambrosettianus (Ameghino, 1889, Rodentia, Caviomorpha, Neoepiblemidae) do Mioceno superior-Plioceno, Estado do Acre, Brasil, e revisão das espécies do gênero. Bol. Mus. Para. Emílio Goeldi, 10:1-80.

Novacek M.J. 1985. Cranial evidence for rodent affinities. In: Luckett W.P., Hartenberger J.L. Evolutionary relationships among rodents: a multidisciplinary analysis. New York: Plenum Press. p. 59-81.

Oliveira E.V. 1992. Mamíferos fósseis do Quaternário do Estado do Rio Grande do Sul, Brasil. Porto Alegre: PósGrad. Geoc. UFRGS. 118 p. (Dissert. Mestrado). 
Oliveira L.D.D., Souza-Cunha F.L, Locks M. 1985. Um Hydrochoeridae (Mammalia, Rodentia) no Pleistoceno do nordeste o Brasil. In: Campos D.A., Ferreira C.S., Brito I.M., Viana C.F. org. 1985. Coletânea de Trabalhos Paleontológicos, DNPM. p. 93-97.

Oliveira P.V., Ribeiro A.M., Kerber, L., Viana, M.S.S., Lessa, G. 2013. Late Quaternary Caviomorph Rodents (Rodentia: Hystricognathi) from Ceará State, Northern Brazil. J. Caves Karst. Stud., 75:81-91.

O’Leary M.A., Bloch J.I., Flynn J.J., Gaudin T.J., Giallombardo A., Giannini N.P., Goldberg S.L., Kraatz B.P., Luo Z.X., MengJ., NiX., Novacek M.J., Perini F.A., Randall Z.S., Rougier G.W., Sargis E.J., Silcox M.T., Simmons N.B., Spaulding M., Velazco P.M., Weksler M., Wible J.R., Cirranello A.L. 2013. The placental mammal ancestor and the Post-K-Pg radiation of placentals. Science, 339(662):662-667.

Opazo J.C.A. 2005. Molecular timescale for caviomorph rodents (Mammalia, Hystricognathi). Mol. Phylogenet. Evol., 37:932-937.

Parada A., Pardiñas U.F.J., Salazar-Bravo J., D’Elía G., Palma, R.E. 2013. Dating an impressive Neotropical radiation: molecular time estimates for the Sigmodontinae (Rodentia) provide insights into its historical biogeography. Mol. Phylogenet. Evol., 66:960-968.

Patterson B. 1942. Two tertiary mammals from northern South America. Am. Mus. Novit., 1173:1-8.

Patterson B., Wood, A.E. 1982. Rodents from the Deseadan Oligocene of Bolivia and the relationships of the Caviomorpha. Bull. Mus. Comp. Zool., 149: 371-543.

Patton J., Catzeflis, F., Weksler, M., Percequillo, A. 2008a. Makalata didelphoides. IUCN Red List of Threatened Species. Version 2013.2. URL: www.iucnredlist. org. Acesso 28/07/2014.

Patton J., Catzeflis, F., Weksler, M., Percequillo, A. 2008b. Makalata macrura. IUCN Red List of Threatened Species. Version 2013.2. URL: www.iucnredlist. org. Acesso 28/07/2014.

Patton J., Catzeflis, F., Weksler, M., Percequillo, A. 2008c. Makalata obscura. IUCN Red List of Threatened Species. Version 2013.2. URL: www.iucnredlist.org. Acesso 28/07/2014.

Patton J.L., Leite R.N. 2015. Genus Proechimys. In: Patton J.L., Pardiñas U.F.J. D'Elía GD. eds. Mammals of South America, Volume 2 - Rodents. Chicago: Univ. of Chicago Press. p. 950-989.

Paula Couto C. 1950. Peter Wilhelm Lund-Memórias sobre a paleontologia brasileira. Rio de Janeiro: Min. da Educação e Saúde/ Inst. Nacional do Livro. 589 p.

Paula Couto C. 1951. Uma espécie do gênero Tetrastylus Ameghino, 1886, em Lagoa Santa. Bol. Mus. Nac. Geologia, 15:1-16.

Paula Couto C. 1978a. Fossil mammals from the Cenozoic of Acre, Brazil. 2. Rodentia Caviomorpha Dinomyidae. Iheringia, Série Geologia, 5:3-17.

Paula Couto C. 1978b. Mamíferos fósseis do Pleis- toceno do Espírito Santo. An. Acad. Bras. Cienc., 50(3):365-379.

Paula Couto C. 1979. Tratado de Paleomastozoologia. Rio de Janeiro: Acad. Bras. Ciências. 590 p.

Paula Couto C. 1983.Fossil mammals from the Cenozoic of Acre, Brazil. 5. Miscellanea. Iheringia, Série Geologia, 8:101-108.

Percequillo A., Patton J. 2008. Echimys vieirai. In: IUCN 2013. IUCN Red List of Threatened Species. Version 2013.2. URL: www.iucnredlist.org. Acesso 29/03/2014.

Pérez E.M. 1992. Agouti paca. Mamm. Species, 404:1-7.

Pérez M.E. 2010. A new rodent (Cavioidea, Hystricognathi) from the middle Miocene of Patagonia, mandibular homologies, and the origin of the crown group Cavioidea sensu stricto. J Vertebr Paleontol., 30(6):1848-1859.

Prevosti F.J., Pardiñas U.F.J. 2009. Comment on "The oldest South American Cricetidae (Rodentia) and Mustelidae (Carnivora): Late Miocene faunal turnover in central Argentina and the GreatAmerican Biotic Interchange" by D.H. Verzi and C.I. Montalvo [Palaeogeogr. Palaeoclimatol. Palaeoecol., 267 (2008) 284-291]. Palaeogeogr. Palaeoclimatol. Palaeoecol., 280:543-547.

Rasia L.L., Candela A.M. 2017. Reappraisal of the giant caviomorph rodent Phoberomys burmeisteri (Ameghino, 1886. from the late Miocene of northeastern Argentina, and the phylogeny and diversity of Neoepiblemidae. Hist. Biol. Forthcoming.

Reis M., Lacher T. 2008. Carterodon sulcidens. In: IUCN 2013. IUCN Red List of Threatened Species. Version 2013.2. URL www.iucnredlist.org. Acesso 13/01/2014.

Reis S.F., Pessôa L.M. 2004. Thrichomys apereoides. Mamm. Species, 741:1-5.

Reig O.A. 1981. Teoría del origen y desarrollo de la fauna de mamíferos de América del Sur. Monografia Naturae, Museu Municipal de Ciencias Naturales "Lorenzo Scaglia, 1:1-161.

Reig O. 1984. Distribuição geográfica e história evolutiva dos roedores muroideos sulamericanos (Cricetidae: Sigmodontinae). Rev. Bras. Genet., 7:333-365.

Ribeiro A.M., Madden R.H., Negri F.R., Kerber L., Hsiou A.S., Rodrigues K.A. 2013. Mamíferos fósiles y biocronología en el suroeste de la Amazonia, Brasil. Asociación Paleontológica Argentina - Pub. Esp., 14:207-221.

Rinderknecht A., Blanco R.E. 2008. The largest fossil rodent. Proc. R. Soc. Lond. B. Biol Sci., 275:923-928

Rodrigues P.H., Ferigolo J. 2004. Roedores pleistocênicos da Planície Costeira do Estado do Rio Grande do Sul, Brasil. Rev. Bras. Paleontolog., 7(2):231-238.

Roth P.R.O., Jung D.M.H., Christoff A.U. 2008. Identificação de remanescentes de roedores de um abrigo sob rocha do Nordeste do RS: implicações paleoambientais. Revista de Iniciação Científica da Ul- 
bra, 1:71-82.

Rowe D.L., Honeycutt, R.L. 2002. Phylogenetic relationships, ecological correlates, and molecular evolution within the Cavioidea (Mammalia, Rodentia). Mol. Biol. Evol., 19: 263-77.

Rowe D.L., Huchon D., Madsen O., Sibbald M.J.J.B., Ament K., Stanhope M.J., Catzeflis F., De Jong W.W., Douzery E.J.P. 2002. Rodent phylogeny and a timescale for the evolution of Glires: evidence from an extensive taxon sampling using three nuclear genes. Mol. Biol. Evol., 19:1053-1065.

Rusconi C. 1933. Apuntes sobre algunos restos de mamíferos fosiles procedentes del Brasil. Bol. Soc. Geol. Perú, 5:23-26.

Salles L.O., Carvalho G.S., Weksler M., Sicuro F.L., Abreu F., Camardella A.R., Guedes, P.G., Avilla L.S., Abrantes E.A.P., Sahate V., Costa I.S.A. 1999. Fauna de mamíferos do Quaternário de Serra da Mesa (Goiás, Brasil). Publ. avulsas mus. nac,, 78:1-15.

Salles L.O., Cartelle C., Guedes P.G., Boggiani P.C., Janoo A., Russo C.A. 2006. Quaternary mammals from Serra da Bonoquena, Mato Grosso do Sul, Brazil. Bol. Mus. Nac., N. S., Zool., 521:1-12.

Sánchez-Villagra M.R., Aguilera O., Horovitz I. 2003. The anatomy of the world's largest extinct rodent. Science, 301:1708-1710.

Sant'Anna-Filho M.J. 1994. Roedores do Neógeno do Alto Juruá, Estado do Acre, Brasil. Porto Alegre: Pós-Grad. Geoc. UFRGS. 167 p. (Dissert. Mestrado).

Sant'anna-Filho M.J. 1997. Novos registros de Neoepiblemidae do Neógeno do Alto Juruá, Estado do Acre. In: Congresso Brasileiro De Paleontologia, 15, 1997. São Pedro. Livro de Resumos, São Pedro. p. 124.

Simpson G.G. 1980. Splendid Isolation: The curious history of South America Mammals. New Haven and London: Yale Univ. Press. 275 p.

Souza-Cunha F.L., Guimarães M.L. 1978. A fauna sub-recente de vertebrados do "Grande Abrigo da Lapa Vermelha Emperaire (P.L.)" Pedro Leopoldo, Estado de Minas Gerais. Arquivos do Museu de História Natural da Universidade Federal de Minas Gerais, 3:201-238.

Souza-Cunha F.L., Magalhães, R.M.M. 1986. A fauna de vertebrados sub-recentes de Cerca Grande, Matozinhos, Minas Gerais. Publ. avulsas mus. nac, 65:119-131.

Springer M.S., Stanhope M.J., Madsen O., Jong W.W. 2004. Molecules consolidate the placental mammal tree. Trends Ecol. Evol., 19(8):430-438.

Stehlin H.G., Schaub S. 1951. Die trigonodontie der simplicidentaten Nager. Schweizerische Palaeontologisches Abhandlungen, 67:1-385.

Sussman D.R. 2011. The erethizontid fossil from the Uquía formation of Argentina should not be referred to the genus Erethizon. South Am. Earth Sci., 31:475-478.

Tirira D., Solari S. Echimys saturnus. In: IUCN 2013. IUCN Red List of Threatened Species. Version 2013.2.
URL< <www.iucnredlist.org>. Acesso 29/03/2014.

Tognelli M. F., Campos C. M., Ojeda R.A. 2001. Microcavia australis. Mamm. Species, 648:1-4.

Toledo P.M., Moraes-Santos H.M., Souza De Melo C.C. 1999. Levantamento preliminar de mamíferos não-voadores da Serra dos Carajás: grupos silvestres recentes e zooarqueológicos. Bol Mus Para Emílio Goeldi, 15(2):141-157.

Tullberg T. 1889. Ueber das System der Nagethiere, eine phylogenetische Studie. Upsala: Druck der Akademischen Buchdruckerei. 514 p.

Ubilla M. 1996. Paleozoología del Cuaternário continental de la Cuenca Norte del Uruguay: Biogeografia, Cronologia y aspectos climático-ambientales. Montevideo: UR, Montevideo. 232p. (Tesis Doctoral).

Ubilla M. 2008. Late Pleistocene hystricognath rodents (Mammalia) in mid-latitudes of South America (Uruguay): insights in biogeographic and paleoenvironmental studies. In Ann. Symp. Vertebr. Palaeont. Compar. Anatomy, 56, 2008. Programe \& Abstracts, Dublin. p. 53-54.

Ubilla M., Oliveira E.V., Rinderknecht A., Pereira J. 2008. The hystricognath rodent Microcavia in the Late Pleistocene of Brazil (Rio Grande do Sul, South America) (Mammalia: Caviidae). Biogeographic and paleoenviromental implications. Jahrb. Geol. Palaontol/Abhandlungen, 247(1):15-21.

Ubilla M., Rinderknecht A. 2001. Consideraciones sobre el género Galea Meyen, 1831 (Rodentia, Caviidae), su registro en el Pleistoceno de Uruguay y descripción de una nueva especie extinguida. Bol. R. Soc. Esp. Hist. Nat. Secc. Biol., 96(3-4):111-122.

Ubilla M., Rinderknecht A. 2014. Comparative analysis of Galea (Rodentia, Caviidae) andexpanded diagnosis of Galea ortodonta Ubilla and Rinderknecht, 2001 (late Pleistocene, Uruguay). Geobios, 47:255-269.

Upham N.S., Patterson B.D. 2015. Evolution of the caviomorph rodents: a complete phylogeny and time tree of living genera. In: Vassallo A.I., Antenucci D. eds. Biology of caviomorph rodents: diversity and evolution. Buenos Aires: SAREM Series A. p. 63-120.

Vélez-Juarbe J., Martin T., Macphee R.D.E., Ortega-Ariza, D. 2014. The earliest cariben rodents: Oligocene caviomorphs from Porto Rico. J Vertebr $\mathrm{Pa}$ leontol., 34(1):157-163.

Veniaminova N.A., Vassetzky N.S., Lavrenchenko L.A., Popov S.V., Kramerov D.A. 2007. Phylogeny of the Order Rodentia Inferred from Structural Analysis of Short Retroposon B1. Russ. J. Genet., 43(7):757-768.

Verzi D.H., Montalvo C. I. 2008. The oldest South American Cricetidae (Rodentia) and Mustelidae (Carnivora): Late Miocene faunal turnover in central Argentina and the Great American Biotic Interchange. Palaeogeogr. Palaeoclimatol. Palaeoecol., 267:284-291.

Voss R.S. 2011. Revisionary notes on neotropical porcupines (Rodentia: Erethizontidae) 3. An annotated 
checklist of the species Coendou Lacépède, 1799. Am. Mus. Novit., 3720:1-36.

Vucetich M.G. 1984. Los roedores de la Edad Friasense (Mioceno medio) de Patagonia. Rev. Mus. La Plata, 8:47-126.

Vucetich M.G., Arnal M., Deschamps C.M., Pérez M.E., Vieytes E.C. 2015b. A brief history of caviomorph rodents as told by the fossil record. In: Vassallo A., Antonucci D. (ed). 2015. Biology of Caviomorph Rodents: Diversity and Evolution. Buenos Aires: Sociedad Argentina para el estudio de los Mamíferos. p 11-62.

Vucetich M.G., Carlini A.A., Aguilera O., Sanchez-Villagra M. 2010b. The Tropics as Reservoir of Otherwise Extinct Mammals: The Case of Rodents from a New Pliocene Faunal Assemblage from Northern Venezuela. J. Mammal. Evol., 17(4):265-273.

Vucetich M.G., Deschamps C.M., Olivares A.I., Dozo M.T. 2005. Capybaras, size, shape, and time: a model kit. Acta Palaeontol. Pol., 50:259-272.

Vucetich M.G., Deschamps C.M., Pérez M.E. 2012. Paleontology, Evolution and Systematics of Capybara. In: Moreira J.R., Ferraz K.M.P.B.M., Herrera H.A., Macdonald D.W. 2012. Capybara: Biology, use and conservation of an exceptional Neotropical species. New York: Springer Science and Business Media. p. 39-59.

Vucetich M.G., Deschamps C.M., Pérez M.E. 2015a. The first capybaras (mammalia, Cavidae, Hydrochorinae) Involved in the Great American Biotic Interchange: Ameghiana, 52(3):324-333.

Vucetich M.G., Ribeiro, A.M. 2003. A New and primitive rodent from the Tremembé Formation (Late Oligocene) of Brazil, with comments on the morphology of the lower premolars of the caviomorphs rodents. Rev. Bras. Paleontolog., 5(5):73-83.

Vucetich M.G., Souza Cunha F.L., Alvarenga H.M.F. 1993. Un roedor Caviomorpha de la Formación Tremembé (Cuenca de Taubaté), Estado de São Paulo, Brasil. An. Acad. Bras. Cienc., 65: 247-251.

Vucetich M.G., Verzi D.H. 1999. Changes in Diversity and Distribution of the Caviomorph Rodents during the Late Cenozoic in South America. Quat. S. Am. A., 12:207-223.

Vucetich M.G., Verzi D.H. 2002. First record of Dasyproctidae (Rodentia) in the Pleistocene of Argentina. Paleoclimatic implication: Palaeogeogr. Palaeoclimatol. Palaeoecol., 178:67-73.

Vucetich M.G., Verzi D.H., Tonni E.P. 1997. Paleoclimatic implications of the presence of Clyomys (Rodentia, Caviomorpha) in the Upper Pliocene of Buenos Aires Province. Palaeogeogr. Palaeoclimatol. Palaeoecol., 128:207-214.

Vucetich M.G., Verzi D.H., Hartenberger J.L. 1999. Review and analysis of the radiation of the South American Hystricognathi (Mammalia, Rodentia). C.R. Acad. Sci., 329:763-769.

Vucetich M.G., Vieytes E.C., Pérez M.E., Carlini A.A. 2010a.The rodents from la Cantera and the early evolution of caviomorphs in South America. In: Madden R.H., Carlini A.A., Vucetich M.G., Kay R.F. 2010. The paleontology and geology Gran Barranca: Evolution and environmental change through Middle Cenozoic of Patagonia. Cambridge: Cambridge Univ. Press. p. 193-205.

Zeballos H., Vivar E., Patterson B. 2008. Makalata rhipidura. IUCN Red List of Threatened Species. Version 2013.2. URL: <www.iucnredlist.org>. Acesso 28/07/2014.

Walton A.H. 1997. Rodents. In: Kay R.F., Madden R.H., Cifelli R.L., Flynn J.J. eds. 1997. Vertebrate Paleontology in the Neotropics: The Miocene Fauna of La Venta, Colombia. Washington: Smithsonian Institution Press. p. 392-409

Wilson D.E., Reeder D.M. 2005. Mammal species of the world: a taxonomic and geographic reference. 3. ed. Maryland: Johns Hopkins Univ. Press. 2142 p.

Winge, H. 1887. Jordfundne og Nulevende gnavere (Rodentia) fra Lagoa Santa, Minas Geraes, Brasilien. E Museo Lundii, 3:1-178.

Wood, A.E. 1954. Comments on the classification of rodents. Breviora, 41:1-9.

Wood A.E. 1955. A revised classification of the Rodents. J. Mammal., 36(2):165-187.

Wood A.E. 1965. Grades and clades among rodents. Evolution, 19: 115-130

Wood A. 1972. An Eocene hystricognathous rodent from Texas: its signigicance in interpretations of continental drift. Science, 175:1250-1251.

Wood A.E. 1973. Eocene rodents, Pruett Formation, southwest Texas, their pertinence to the origino f the South American Caviomorpha. The Pearce-Sellards Series, 20:1-41.

Wood A.E., Patterson, B. 1959. The rodents of the Deseadan Oligocene of Patagonia and the beginnings of South American rodent evolution. Bull. Am. Mus. Nat. Hist., 120:279-428.

Wood A.E. Patterson, B. 1970. Relationships among hystricognathous and hystricomorphous rodents. Extrait de Mammalia, 34(4):630-639.

Woodburne, M.O. 2010. The Great American Biotic Interchange: Dispersals, Tectonics, Climate, Sea Level and Holding Pens. J. Mammal. Evol., 17: 245-264.

Woodburne M.O., Cione A.L., Tonni E.P. 2006. Central American provincialism and the Great American Biotic Interchange. In: Carranza-Castañeda O., Lindsay E.H. eds. Advances in late Tertiary vertebrate paleontology in Mexico and the Great American Biotic Interchange. Univ. Nac. Autón. México, Inst. Geol. y Centro Geoc., Publ. Esp., 4:73-101.

Woods C.A., Kilpatrick C.W. 2005. Infraorder Hystricognathi. In: Wilson D.E., Reeder D.M. eds. Mammal Species of the World: A Taxonomic and Geographic Reference. 3rd ed. Baltimore: Johns Hopkins Univ. Press. p. 1538-1600.

Woods C.A., Contreras L., Willner-Chapman G., Whidden H.P. 1992. Myocastor coypus. Mamm. Species, 
398:1-8.

Wu S., Wu W., Zhang F., Ye J., Ni X., Sun J., Edwards S. V., Meng J., Organ C.L. 2012. Molecular and Paleontological Evidence for a Post-Cretaceous Origin of Rodents. Plos One, 7(10): e46445.
Wyss A.R., Flynn J.J., Norell M.A., Swisher Iii C.C., Charrier R., Novacek M.J., Mckenna M.C. 1993. South America's earliest rodent and recognition of a new interval of mammalian evolution. Nature, 365: 434-437.

Resumo: Rodentia é um dos grupos de mamíferos placentários mais diversificados. Representantes desse clado possuem uma ampla distribuição geográfica, ocupando todos os continentes, com exceção da Antártida. Entre as diversas linhagens que compõem Rodentia, destacam-se os Caviomorpha, um grupo de origem sul-americana. Caviomorfos surgem no registro fossilífero durante 0 Eoceno médio, passando por diversos períodos de diversificação ao longo do Cenozoico, principalmente durante o final do Oligoceno e Mioceno médio/final. Aqui compilamos as informações sobre o registro fossilifero desse grupo no território brasileiro e discutimos aspectos em relação à sistemática, morfologia, ecologia, evolução e implicações dos fósseis. Fósseis dos seguintes grupos têm sido coletados em nosso país: Erethizontidae (Erethizontoidea), Echimyidae, Ctenomyidae (Octodontoidea), Caviidae (incluindo Hydrochoerinae), Dasyproctidae, Cuniculidae (Cavioidea), Chinchillidae, Dinomyidae e Neoepiblemidae (Chinchilloidea). Os fósseis encontrados nessa porção do continente têm ajudado a contar parte da história evolutiva dos caviomorfos durante 0 Oligoceno final, Neógeno e Quaternário. Como futuras perspectivas no estudo dos fósseis de roedores do Brasil, espera-se que a coleta com controle estratigráfico de novos espécimes, revisão de fósseis depositados em coleções científicas e refinamento do conhecimento sobre a morfologia das unidades taxonômicas contribuirão para uma melhor compreensão sobre a diversidade e evolução desse grupo.

Palavras chave: Caviomorfos, história evolutiva, paleobiogeografia, Paleógeno, Neógeno, Quaternário. 